Canadian

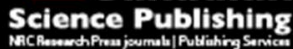

Canadian Geotechnical Journal Revue canadienne de géotechnique

\title{
Bucket Foundation Model Testing under Tensile Axial Loading (re-submission of cgj-2015-0497)
}

\begin{tabular}{|r|l|}
\hline Journal: & Canadian Geotechnical Journal \\
\hline Manuscript ID & cgj-2016-0301 \\
\hline Manuscript Type: & Article \\
\hline Date Submitted by the Author: & 01 -Jun-2016 \\
\hline Complete List of Authors: & $\begin{array}{l}\text { Vaitkune, Evelina; Aalborg University, Civil Engineering } \\
\text { Ibsen, Lars; Aalborg University, Denmark, Civil Engineering } \\
\text { Nielsen, Benjaminn; Aalborg University, Civil Engineering }\end{array}$ \\
\hline Keyword: & $\begin{array}{l}\text { bucket foundation, tensile loading, axial loading, cyclic loading, long-term } \\
\text { loading }\end{array}$ \\
\hline
\end{tabular}

\section{SCHOLARONE ${ }^{\mathrm{m}}$}

Manuscripts 
$1 \quad i$. Title of the paper:

2 Bucket Foundation Model Testing under Tensile Axial Loading

3

4 ii. Authors:

1. Evelina Vaitkune

iii. Affiliation and address for each author:

iv. The author responsible for correspondence:

Evelina Vaitkune, Ph.D. student, 


\section{Abstract}

46 The present study focusses on the bucket foundation behaviour under long-term cyclic loading.

47 The paper analyses model testing results of a bucket foundation model exposed to cyclic tensile 48 loading. The model dimensions are $1 \mathrm{~m}$ in diameter and $0.5 \mathrm{~m}$ in skirt length. It is installed in 49 dense water-saturated sand. Slow monotonic loading tests and cyclic tensile loading tests are 50 performed (up to 40,000 load cycles) including tests with mean cyclic load in tension which is 51 unique in this sense. High quality data is documented for load, displacement and pore pressure 52 response. Conclusions are drawn regarding static and cyclic loading stiffness and displacement 53 development during the long-term cyclic loading. Four cyclic loading tests induced partially 54 drained soil conditions and showed that pore pressure can accumulate during the long-term 55 loading. Post-cyclic monotonic tensile loading tests showed up to $25 \%$ reduction in capacity.

56 The research results supply valuable information for the design of an upwind bucket foundation 57 under a jacket structure.

59 Keywords: bucket foundation, tensile loading, axial loading, cyclic loading, long-term

60 loading, $1 g$ testing, dense sand

61

62

63

64

65

66

67

68

69

70 
Introduction

76 Bucket foundations have been used for decades as a suitable support for various offshore 77 structures in the oil and gas industry. Tjelta (2015) thoroughly explains the development of 78 suction foundation technology including historical overview and main features. Currently, interest is growing for building extra-large, but still relatively light and very slender wind turbines in deep waters. Compared to an oil platform, a large wind turbine has a small self-weight. To stand in deep water, a wind turbine can be supported on a multi-foundation system. Thus, the large horizontal loading coming from wind and waves would be transferred to dominating axial loads on each foundation. An optimal foundation design solution for extra-large wind turbines should be found, and it is not a straight forward process for two reasons: firstly, the foundations should be cost-effective; and secondly, they should be able to resist tensile loading. In some cases, a long-term cyclic tensile loading would be unavoidable unless the spacing between each foundation is increased or an additional dead-load is placed.

Until today, a significant number of bucket foundation studies were performed at several research institutes and universities, among the best known are Oxford University, Norwegian Geotechnical Institute and Aalborg University. At Aalborg University, monopod bucket foundations were analysed in detail by Feld et al. (1999 and 2000), Larsen et al. (2013), Foglia and Ibsen (2013) and Barari et al. (2015).

An extensive study at Oxford University focussed on axially loaded suction caisson foundations. It included tests with caisson foundation models in different soils in a pressure chamber (Kelly et al. 2003) as well as a large-scale field testing (Kelly et al. 2006a). Most of the times, the performed cyclic loading tests had mean compressive loading and a small part of the loading amplitude was tensile; the highest number of cycles was 1000. It was claimed that, to have a safe design, the highest tensile loading acting on a bucket foundation should be limited to the drained friction resistance (Kelly et al. 2003, 2004, 2006a and 2006b). Thus, the tensile capacity would consist of friction on the outer skirt, self-weight of the structure and the lower of the soil plug weight and the inner skirt friction. Byrne and Houlsby (2006) stated that the tension on the upwind foundation should be generally avoided. However, limited amount of model testing data 
105 is publicly available focussing on the cyclic tensile loading on bucket foundations, especially 106 with high cycle number and various mean tensile loads.

107

108 A medium-scale bucket foundation model, corresponding to 1:10 prototype size, was used for 109 the testing of load, displacement and pore pressure response in a $1 g$ testing rig. Cyclic loading 110 program consisted of up to 40,000 constant load amplitude cycles followed by a final monotonic 111 pull-out quantifying the cyclic degradation of the frictional resistance. Furthermore, dimensional 112 analysis on stiffness and displacement was applied according to Kelly et al. (2006a). Through 113 the physical model testing, this paper aims at visualizing the bucket foundation behaviour under 114 long-term cyclic loading conditions. The influence of the axial tensile load on the displacement 115 and cyclic degradation is studied.

116

117 Equipment and testing

118 Quasi-static and permanent loads, such as mean cyclic loads, induce drained conditions in soil. 119 Under drained conditions, the tensile capacity of the bucket foundation corresponds to the dead 120 load of the structure and the frictional resistance generated in the soil-structure interface. 121 Furthermore, it is a lower bound solution for the tensile capacity. This was taken as a starting 122 point in the present model testing program which focussed on the drained response of the 123 bucket foundation model examined by a specially designed laboratory test set-up.

The laboratory test facility was launched in 2013 and presented for the first time by Vaitkunaite et al. (2014). The test set-up consisted of a large sand container, an installation, a loading frame equipped with two hydraulic cylinders and an automatic load regulation system. The tests presented in this article were performed with bucket foundation model of $1 \mathrm{~m}$ in diameter $D, 0.5$ $\mathrm{m}$ in skirt length $d$ and $3 \mathrm{~mm}$ skirt thickness $t$, which corresponds to prototype foundation with $d / D$ ratio 0.5 . The bucket is made of steel and has a self-weight of $204 \mathrm{~kg}$ including the connection flange between the model and the load application point, see Fig. 1. 
135 The rigid sand container had an inner diameter of $2.5 \mathrm{~m}$. It was filled with $0.3 \mathrm{~m}$ of gravel used 136 for drainage and $1.2 \mathrm{~m}$ of Aalborg University sand No. 1 (Fig. 1). The latter is quartz sand which 137 contains a small part of biotite and feldspar. The small sand particles are sub-angular while the 138 larger particles are rounded. The main sand properties were as follows: specific grain density $1392.64 \mathrm{~g} / \mathrm{cm}^{3}$, lowest void ratio $e_{\min } 0.549$, highest void ratio $e_{\max } 0.858,50 \%$-quantile $0.14 \mathrm{~mm}$, 140 uniformity coefficient 1.78. Borup and Hedegaard (1993) and Ibsen and Boedker (1994) 141 thoroughly reported the sand properties. Fig. 3 shows particle size distribution performed by 142 sieve analysis. The sand was saturated and compacted to a planned density level before every 143 test. Aalborg University sand No. 1 has a hydraulic conductivity of $8 \times 10^{-5} \mathrm{~m} / \mathrm{s}$ when prepared to relative density $D_{R}=80 \%$. Sjelmo (2012) performed a permeability analysis of Aalborg University sand No. 1 through a falling head apparatus.

\section{Testing procedure and data sampling}

148 Vaitkunaite et al. (2014) described testing procedure that was applied for this program. To begin 149 with, the sand was loosened with an upward gradient. Afterwards, the sand volume was 150 compacted by a rod vibrator. Later on, at least four small-scale laboratory cone penetration 151 tests (CPT) were performed to inspect soil conditions. Larsen (2008) described the laboratory 152 CPT device and the methodology for the CPT interpretation. Ibsen et al. (2009) estimated $D_{R}$ 153 from the laboratory cone resistance. Tests presented in this article were performed in dense 154 sand with $D_{R} \approx 80 \%$, see Table 1 .

155 Mechanical push installation of bucket foundation models was used by Kelly et al. (2003), Kelly et al. (2006a) and Foglia (2015). Kelly et al. 2006a compared installation by suction and pushing and documented that the soil disturbance due to suction installation was more visible in smallscale model tests, probably, because of local soil disturbances which do not increase in proportion to caisson diameter. It is expected that suction installation loosens soil in the inner interface zone and reduces the strength properties of soil-structure interface in a short-term. However, the properties are probably regained after some time due to small cyclic wave loading which is typical in summer weather conditions. Nielsen (2016) performed laboratory tests with 
164 bucket foundation models. He showed that a bucket foundation model gained 1.6 times larger 165 bearing capacity when pre-loaded with small load cycles. This study dealt with the foundation 166 model installed by mechanical pushing, because the focus was operational loading discharging 167 the installation impact.

168

169 Installation started with positioning the bucket right on the soil surface level, zeroing the signal 170 of the load cell and penetrating the bucket skirt down to the soil with $0.2 \mathrm{~mm} / \mathrm{s}$ velocity. Two 171 large valves were kept open during the installation to let the air flow out. The installation ended 172 when approximately $70 \mathrm{kN}$ force was reached. Right after that, the model was completely 173 unloaded. The installation required about $50 \mathrm{kN}$ force from the hydraulic cylinder. An elastic compressive preload of $20 \mathrm{kN}$ ensured that the bucket was fully installed and kept the 175 procedure repetitive (Fig. 4). In most of the cases, during the installation, the water table was about $3 \mathrm{~cm}$ above sand surface. During installation procedure, it was noticed that the load cell reacted to the lid contact with the water table. In a few tests, were the water table was at the same level of the sand surface, only one change in the response was noticed corresponding to the level of the soil surface. This means that the installation rate was slightly higher than would be required for completely drained soil response. However, the installation velocity was limited by the equipment and could not be lower than $0.2 \mathrm{~mm} / \mathrm{s}$. Thus, bucket model was left to rest in the sand at least 2 hours allowing pore pressure dissipation. Load and position signals were measured during the installation process with sampling frequency of $1 \mathrm{~Hz}$.

The testing program of the monotonic tensile loading and cyclic loading tests is presented in details in the following section. Load, displacement and pore pressure responses were measured during the tests. Load cell had a capacity of $250 \mathrm{kN}$ and was positioned right above the foundation model. Position of the hydraulic cylinder piston was measured with a displacement transducer. Additionally, two displacement transducers were placed on the lid of the foundation model; they could measure displacements of up to $125 \mathrm{~mm}$. To analyse the drainage conditions, pore pressure response was measured at different levels on the model skirt. Pore pressure transducers were placed above the bucket model and connected to measuring positions via narrow water-filled pipes. As the cyclic tests typically took up to five 
194

195

196

197

198

199

200

201

202

203

204

205

206

207

208

209

210

211

212

213

214

215

216

217

218

days, the atmospheric pressure changes were also measured and separated from the pore pressure measurements. Fig. 2 shows all the mentioned transducers. Data sampling rate depended on the type of loading, i.e. $1 \mathrm{~Hz}$ frequency was chosen for monotonic loading tests and $2 \mathrm{~Hz}$ frequency for cyclic loading tests.

MOOG modular test controller was used to control and monitor various loading regimes; for example, tension, compression and periodic loading with various force or displacement amplitudes and frequencies. The system was able to work continuously for several days, which was important for the high cycle number loading tests.

\section{Loading program}

Before describing the loading program, it is worth mentioning that tensile loading, upward displacement and suction pore pressure are marked with a negative sign or drawn on the negative axis.

For the presentation of the load cases, two parameters were used to characterise the cyclic axial loading, i.e. $\xi_{A}$ and $\xi_{m}$. Ratio $\xi_{A}$ (eq. 1 ) describes the cyclic loading amplitude $F_{c y c}$ normalized with reference monotonic tensile load $F_{T R} . \xi_{A}$ takes a value from 0 to 1 , where $F_{c y c}$ equal to $F_{T R}$ results in $\xi_{A}=1$ and the smaller $F_{c y c}$ results in $\xi_{A}<1$. The second parameter (eq. 2 ) expresses the ratio between the mean cyclic load $F_{\text {mean }}$ and the reference monotonic tensile capacity $F_{T R} . \xi_{m}$ takes a value from -1 to 1 , where mean tensile cyclic load equal to $F_{T R}$ results in $\xi_{m}=-1$ while mean compressive cyclic load equal to $\left|F_{T R}\right|$ results in $\xi_{m}=1$. A perfect two-way cyclic loading with $F_{\text {mean }}=0$ results in $\xi_{m}=0$. Fig. 5 visualizes the mentioned loading parameters.

(1) $\xi_{A}=-\frac{F_{c y c}}{F_{T R}}$

(2) $\xi_{m}=-\frac{F_{\text {mean }}}{F_{T R}}$ 
219 In the first set of tests, the monotonic tensile capacity was measured. The tests were position 220 controlled with maximum vertical pull-out velocity of $0.002 \mathrm{~mm} / \mathrm{s}$ which ensured that the soil 221 response was drained.

222

223 The second set of tests focussed on drained behaviour of bucket foundation subjected to cyclic 224 axial loading. Sinusoidal cyclic loading with constant amplitude and mean load was applied on 225 the model. Loading frequency $f$ was $0.1 \mathrm{~Hz}$, except in one test presented in this paper where the 226 frequency was $0.05 \mathrm{~Hz}$. Each time, the testing program consisted of more than 20,000 load controlled cycles followed by a position controlled monotonic pull-out $F_{P c}$.

228

\section{Test results}

230 All monotonic tensile loading tests showed very similar behaviour and similar tensile peak 231 resistance. Pore pressures did not exceed $1.3 \mathrm{kPa}$ during the loading sequence (Fig. 6), which 232 was within the measuring accuracy of the transducers. Two different displacement rates were 233 applied in the four monotonic tests: two tests with $0.001 \mathrm{~mm} / \mathrm{s}$ and two with $0.002 \mathrm{~mm} / \mathrm{s}$. No 234 influence on the pore pressure transducers was seen for the different displacement rate tests.

235 The displacement rate was extremely low for water saturated sand and it took 1.4-2.8 hours to 236 lift the model only $10 \mathrm{~mm}$. Thus the response was assumed to be drained.

238 It was noticed that the peak tensile load $F_{T}$ was reached within the first $6 \mathrm{~mm}$ upward displacement $(0.006 D)$, which was followed by a continuous decrease in load resistance due to

240 a decrease in the soil-structure interface area and softening behaviour of the soil. The reference monotonic tensile resistance $F_{T R}$ was chosen as the average of $F_{T}$.

243 This paper presents five cyclic loading tests with mean tensile load, three tests with mean 244 compressive load and one with zero mean load. Fig. 7 shows a cyclic loading test followed by a 245 post-cyclic monotonic pull-out. The bucket foundation model was allowed to move up to $-65 \mathrm{~mm}$ 246 upwards $(0.065 D)$. In Table 1, two tests are marked as "pulled"; it refers to vertical upward 247 displacement of $-65 \mathrm{~mm}$. 
249 If no significant displacement rate and pore pressure change were seen, then it was expected 250 that there was no cycle that could exceed the drained tensile capacity. However, during four 251 cyclic loading tests, i.e. A0.3m-0.4:1, A0.3m-0.4:2, A0.7m-0.4:1 and A0.7m-0.4:2, pore pressure 252 build up during the loading sequence was noticed. Loading rate analysis showed that the pore 253 pressure build up was present in the tests where the loading rate was higher than $0.77 \mathrm{kN} / \mathrm{s}$ and 254 mean tensile load was applied in the loading sequence (see Table 1). Pore water pressure 255 during cyclic loading is addressed in section Pore pressure vs. cycles.

256

257 Some of the tests are referred as critical loading tests or tests where a critical load is reached.

258 The critical load in this loading program is the drained tensile resistance $F_{T R}$. The drained soil 259 response is normally assumed for long-term loading conditions. As the main subject of this testing program is drained soil response, the loads reaching $F_{T R}$ are referred as critical.

261

262

\section{Displacement vs. cycles}

263 All the tests had a tendency to either keep the bucket in the initial position or develop upward 264 displacement. During tests with $\xi_{m}=0.3$ and $\xi_{A} \leq 0.7$, the foundation model stayed in the initial position (A0.4m0.3, A0.7m0.3:1, A0.7m0.3:2). Very small upward displacements $(<0.006 D)$ developed in tests with $\xi_{m} \in[-0.4,0]$ and $\xi_{A} \leq 0.3$ (A0.2m0, A0.3m-0.4:1 and A0.3m-0.4:2). Fig. 8 clearly shows that when critical loading was exceeded - the tensile load reached $F_{T R}$ - the bucket eventually was pulled out (A0.7m-0.4:1, A0.7m-0.4:2). However, the foundation model had to be subjected to more than 1,000 cycles of such critical loading to be lifted up to $0.05 D$.

271 Tests $\mathrm{A} 0.7 \mathrm{~m}-0.4: 1$ and $\mathrm{A} 0.7 \mathrm{~m}-0.4: 2$ had identical loading conditions, but slightly different 272 behaviour, the first test required 8 times more cycles to lift the bucket model to $-60 \mathrm{~mm}$ (Fig. 8). 273 Obviously, the displacement rate was changeable in the tests A0.7m-0.4:2 while in A0.7m$274 \quad 0.4: 1$ was rather constant. Furthermore, the inner pore pressure in test A0.7m-0.4:2 decreased 275 constantly (Fig. 13) whereas in the test A0.7m-0.4:1 it was around $0 \mathrm{kPa}$ during the first 5,000 cycles (Fig. 14). This indicated that the accumulation of negative pore pressure resulted in

277 higher displacement. As the loading rate was identical, it should be expected that slightly lower 278 soil permeability (thus, higher $D_{R}$ ) could result in the lower negative pore pressure of test 
279 A0.7m-0.4:2 compared to test A0.7m-0.4:1. Unfortunately, the density ratio was not estimated 280 for the test A0.7m-0.4:2 due to technical issues.

281

282 Kelly et al. 2006b analysed incremental and cumulative cyclic displacement during one test with 283 mean compressive load (referred as Test15) and showed that the incremental displacement 284 decreased within the first 200 cycles and, afterwards, kept constant with a small positive value 285 pushing the bucket model down to the soil at a constant rate. Positive incremental displacement 286 indicates a safe foundation design range, because the bucket cannot be lifted due to the loading 287 conditions.

288

During the present testing campaign it was seen that in most of the examined cases the incremental displacement $w_{i . d}$ became constant within the first 200 loading cycles. Fig. 9 shows accumulated and incremental cyclic displacement during test A0.7m0.3:2. The incremental displacement changed within the first 200 cycles and continued almost constant with a very small positive increment of $10^{-6} \mathrm{~mm}$ until the end of the test. Within the first 200 cycles, the model reached the uppermost position and, afterwards, it was slowly pushed downwards to the initial position $(0 \mathrm{~mm})$. The accumulated displacement during this long-term cyclic loading test was very small $\left(<10^{-3} D\right)$. Similar behaviour was seen in tests A0.7m0.3:1 and A0.4m0.3.

However, all tests with $\xi_{m} \leq 0$ resulted in negative incremental displacements, where average $w_{i . d}$ was in the range from $-10^{-7} \mathrm{~mm}$ to $-10^{-2} \mathrm{~mm}$ depending on loading conditions (see Table 2).

300 Furthermore, under the critical tensile loading, the displacement increment varied during the loading sequence, as seen in Fig. 10. Overall, the negative incremental displacements are small, but they would eventually lead to an inadmissible accumulated displacement of the foundation.

\section{Post-cyclic load}

306 Cyclic degradation is a very important factor that should be evaluated when designing offshore 307 foundations. In this testing program, the cyclic degradation was evaluated comparing the virgin 308 loading response and the post-cyclic loading response. The measured monotonic load 
309 decreased continuously due to a decrease in the soil-structure interface area and softening

310 behaviour. Thus, the corresponding shaft friction was calculated dividing the measured load by

311 the area of the shaft in contact to soil (Fig. 11). The peak post-cyclic shaft friction was very

312 similar to or lower than the virgin shaft friction; in the performed tests, up to $25 \%$ difference in

313 the peak capacity. The peak resistance was reached within the upward displacement of -10

$314 \mathrm{~mm}$, which corresponded to $0.01 D$.

315

316 Pore pressure vs. cycles

317 Shear and dilation occur when dense sands are subjected to external loads. Negative pore 318 pressure occurs if water is unable to flow into the pores when the soil dilates. Dilation is 319 especially high in low soil stresses (shallow depth). As mentioned earlier, the negative pore 320 pressure is limited by the cavitation.

321

322 Until now, no tensile high cycle number tests were performed measuring pore pressure 323 behaviour at different depths of the bucket model skirt. In this testing campaign, it was noticed 324 that pore pressure depends not only on loading rate, but can also change/develop during long325 term cyclic loading as seen in Fig. 12 (test A0.3m-0.4:2). It should be noted that any influence 326 from the atmospheric pressure change during the tests was removed from data, so it shows 327 only the pore pressure state in the soil contact to the foundation model, see also Fig. 2 for the 328 pore pressure measuring positions.

329

330 No pore pressure development (thus, fully drained response) was seen during full loading 331 program in tests $\mathrm{A} 0.2 \mathrm{~m}-0.4, \mathrm{~A} 0.7 \mathrm{~m} 0.3: 1, \mathrm{~A} 0.7 \mathrm{~m} 0.3: 2, \mathrm{~A} 0.4 \mathrm{~m} 0.3 \mathrm{and} \mathrm{A} 0.2 \mathrm{~m} 0$. Small suction 332 accumulation during cyclic loading was visible in tests $A 0.3 m-0.4: 1$ and $A 0.3 m-0.4: 2$ that were subjected to a higher loading rate of $0.77 \mathrm{kN} / \mathrm{s}$ and mean tensile load (Table 1). The highest measured pore pressure reached $-8.5 \mathrm{kPa}$ in test $\mathrm{A} 0.7 \mathrm{~m}-0.4: 2$ which was small compared to the cavitation limit of $-100 \mathrm{kPa}$ (Fig. 12 and Fig. 13). However, the generated suction pressure of $8.5 \mathrm{kPa}$ under the bucket lid resulted in $6.7 \mathrm{kN}$ resistance to tensile load which was larger than

$337 F_{T R}$. As seen in Fig. 13, negative pore pressure was continuously generated through all the 338 loading sequence. Due to measuring accuracy of the pore pressure transducers $(+/-2 \mathrm{kPa})$ it is 
339 hard to say the exact time when drained behaviour changed to partially drained and the tensile 340 resistance was induced by negative pore pressure additionally to the interface friction.

341 Moreover, the pore pressure transducers measured different suction in different levels on the

342 bucket skirt, i.e. the inner part of the bucket was subjected to more suction than the outer 343 indicating partial drainage conditions, see Figs. 2 and 13. As mentioned in section Displacement 344 vs. cycles, the accumulation of the negative pore pressures influenced the displacements. 345 Vaitkunaite et al. 2016 performed experimental analysis with a bucket foundation model in a 346 pressure tank. The analysis confirmed that pore suction level is closely related to upward 347 displacement rate. More analysis of this matter was out of the focus of the present research.

\section{Stiffness during monotonic and cyclic loading}

350 Monotonic loading stiffness during the first $10 \%$ of load, $k_{10 \%}$ was about $11 \mathrm{MN} / \mathrm{m}$, see Fig. 15 for the definition of stiffness. Peak loading stiffness $k_{\text {peak }}$, from the beginning to the peak of the load, was $1.1 \mathrm{MN} / \mathrm{m}$. Post-cyclic tensile load resulted in rather high stiffness. Here $k_{10 \%}$ was very high, i.e. from $46 \mathrm{MN} / \mathrm{m}$ to $3300 \mathrm{MN} / \mathrm{m}$, while the peak loading stiffness $k_{\text {peak }}$ was from 1.0 to $7.3 \mathrm{MN} / \mathrm{m}$.

355

It was noticed that cyclic loading and unloading stiffness were significantly higher than the monotonic loading stiffness and it had similar values to post-cyclic pull-out values of $k_{10 \%}$. Moreover, the stiffness was rather constant during the loading sequence except tests A0.3m-0.4:2 and A0.7m-0.4:2, where the stiffness dropped at some point. Fig. 16 shows that test A0.7m0.3:2 unloading stiffness $k_{c y c}$ was about $230 \mathrm{MN} / \mathrm{m}$ (mean). On the contrary, $k_{c y c}$ was quite low (only $24 \mathrm{MN} / \mathrm{m}$ ) in test $\mathrm{A} 0.7 \mathrm{~m}-0.4: 2$ where large tensile loading dominated. Clear stiffness degradation during cyclic loading was visible only when critical tensile cyclic loading was applied and no degradation in other loading cases.

Kelly et al. 2006a performed cyclic loading tests with mean compressive load and showed that unloading cyclic stiffness had no degradation during cyclic loading, i.e. it was constant or

367 increasing during the loading sequence. Such tendency is confirmed with the present tests, except when critical tensile cyclic loading was applied (tests A0.7m-0.4:1 and A0.7m-0.4:2). 


\section{Dimensional analysis}

371 Kelly et al. 2006a provided equations for comparison of laboratory and field tests which 372 indicated that the method used for data normalization was very successful. Indeed, the study 373 showed good comparability of stiffness in any of the cycles. However, accumulation of 374 deformation during the cyclic loading (90 cycles) had smaller similarity when comparing 375 laboratory and field test data. Analysis of vertically loaded caissons showed that disturbance 376 due to suction installation was less important for field caisson. It is worth mentioning that the 377 dimensional analysis was applied to test data with foundation models having $0.15,0.2$ and 1.5 $378 \mathrm{~m}$ diameter while the present study analyses a foundation model with $1 \mathrm{~m}$ in diameter. 379 Moreover, the loading conditions were quite different compared to the present study, since 380 herein more attention is given to the tensile loading. Model testing data provides valuable knowledge for the full-scale foundation design. Therefore, the application of the theoretical background is of interest.

383

384 Fig. 17 shows the first, middle and last cycles of the corresponding loading sequence in the 385 normalized space. It is clearly seen that test with mean compressive loading (A0.7m0.3:2) 386 presented significantly stiffer behaviour compared to test with mean tensile loading 387 (A0.7m-0.4:2). Softer behaviour of an axially loaded bucket foundation model in tension was 388 also noticed by Kelly et al. 2006a. Actual unloading stiffness is plotted in Fig. 18 which shows 389 that the unloading stiffness was approximately 6.5 times higher in test $A 0.7 m 0.3: 2$. It is 390 impossible to compare directly Kelly et al. 2006a results to the present data, because the load amplitudes herein are much smaller. The softer behaviour of tensile loading tests with negative

\section{Conclusions}

395 The study drew attention to the cyclic tensile loading on a bucket foundation model. The paper presented results from four monotonic and nine cyclic loading model tests where several tests had a mean tensile load which has not been publically documented until now. The medium scale bucket foundation model, corresponding to 1:10 prototype size, was subjected to large 
number of load cycles with various mean loads. Continuous measurements of load, displacement and pore pressures visualized the actual tensile loading behaviour. Based on the performed laboratory tests, the following findings can be drawn:

- Displacement during long-term cyclic loading: All the tests had a tendency to either keep the bucket in the initial position or develop upward displacement. During tests with $\xi_{m}$ from -0.4 to 0.3 and $\xi_{A} \leq 0.3$, the accumulated displacement was smaller than $0.006 D$. Tests with $\xi_{m}=-0.4$ and $\xi_{A}=0.7$ resulted in gradual pull-out. However, the foundation model had to be subjected to more than 1,000 cycles of such critical loading to be lifted up to $0.05 D$.

- A constant negative incremental displacement developed in the tests with $\xi_{m} \leq 0$ which indicated that the bucket foundation would be eventually moved to an inadmissible upward displacement.

- Pore pressure during long-term cyclic loading: Negative pore pressures developed during four tests indicating partially drained behaviour. Consequently, it was noticed that pore pressure can continuously accumulate during long-term cyclic loading.

- Cyclic loading stiffness during long-term cyclic loading: During tests where the mean compressive loading dominated, the cyclic unloading stiffness was higher compared to tests where mean tensile loading dominated. Generally, cyclic stiffness was much higher than monotonic loading stiffness. Clear stiffness degradation during cyclic loading was visible only when critical tensile cyclic loading was applied and no degradation in other loading cases. Unloading stiffness was slightly higher compared to loading stiffness.

- Cyclic degradation: The peak post-cyclic shaft friction was very similar to or lower than the virgin shaft friction; in the performed tests, up to $25 \%$ difference in the peak capacity. The peak tensile resistance was reached within upward displacement of $1 \%$ of bucket diameter $(0.01 D)$.

- Dimensional analysis by Kelly et al. 2006a was applied and visualized well the different trends in the tests for load, displacement and cyclic stiffness development. The 


\section{Acknowledgements}

431 The research was sponsored by project "Cost Effective Foundation and Installation of Wave

432 Energy Converters" through the program ForskEl. The financial support is sincerely

433 acknowledged.

434

\section{References}

436

Barari, A. 2012. Characteristic Behavior of Bucket Foundations. DCE Thesis; No. 36. Department of Civil Engineering, Aalborg University, Aalborg.

Barari, A., Ibsen, L.B., and Foglia, A. 2015. Effect of Load Shape on Impedances of Laterally Loaded Suction Caissons. Canadian Geotechnical Journal. (In press)

Byrne, B.W., and Houlsby, G.T. 2006. Assessing novel foundation options for offshore wind turbines. In Proceedings of World Maritime Technology Conference, London.

Feld, T., Rasmussen, J.L., and Sørensen, P.H. 1999. Structural and Economic Optimization of Offshore Wind Turbine Support Structure and Foundation. In Proceedings of OMAE-99, 18th International Conference on Offshore Mechanics and Artic Engineering, St. Johns Nfld.

Feld, T., Leth, C.T., Mikkelsen, H., and Steenfelt, J.S. 2000. Nyt laboratorieudstyr til simulering af dynamisk påvirkede sugebøttefundamenter. In Proceedings of NGM-2000: XIII Nordiska Geoteknikermötet, Helsinki, p.p. 77-84.

Foglia, A., and Ibsen, L.B. 2013. A Similitude Theory for Bucket Foundations Under Monotonic Horizontal Load in Dense Sand. Geotechnical and Geological Engineering, 31(1): 133-142.

Hedegaard, J., and Borup, M. 1993. Klassifikationsforsøg med Baskard Sand No. 15. Aalborg University, Aalborg.

454 Ibsen, L.B., Hanson, M., Hjort, T., and Thaarup, M. 2009. MC-Parameter Calibration of Baskarp

455 Sand No. 15, DCE Technical Report No. 62, Department of Civil Engineering, Aalborg

$456 \quad$ University, Aalborg. 
457 Kelly, R.B., Byrne, B.W., Houlsby, G.T., and Martin, C.M. 2003. Pressure chamber testing of 458 model caisson foundations in sand. In Proceedings of the international conference on 459 foundations, Dundee, p.p. 421-431.

460 Kelly, R.B., Byrne, B.W., Houlsby, G.T., and Martin, C.M. 2004. Tensile loading of model 461 caisson foundations for structures on sand. In the Fourteenth International Offshore and 462 Polar Engineering Conference. Toulon, 23-28, May 2004. International Society of Offshore 463 and Polar Engineers.

464 Kelly, R.B., Houlsby, G.T., and Byrne, B.W. 2006a. A comparison of field and laboratory tests of 465 caisson foundations in sand and clay. Géotechnique, 56(9): 617-626.

466 Kelly, R.B., Houlsby, G.T., and Byrne, B.W. 2006b. Transient vertical loading of model suction 467 caissons in a pressure chamber. Géotechnique, 56(10): 665-675.

468 Larsen, K.A. 2008. Static Behaviour of Bucket Foundations: Thesis submitted for the degree of 469 Doctor of Philosophy. DCE Thesis; Nr. 7, vol. 1. Department of Civil Engineering, Aalborg $470 \quad$ University, Aalborg.

471 Larsen, K.A., Ibsen, L.B., and Barari, A. 2013. Modified Expression for the Failure Criterion of 472 Bucket Foundations Subjected to Combined Loading. Canadian Geotechnical Journal, $473 \quad 50(12): 1250-1259$.

474 Nielsen S.D. 2016. Transient Monotonic and Cyclic Load Effects on Mono Bucket Foundations. 475 Ph.D. Dissertation. Department of Civil Engineering, Aalborg University, Aalborg. ISSN: 476 2246-1248, ISBN: 978-87-7112-552-8

477 Sjelmo, A. 2012. Soil-structure Interaction in Cohesionless Soils due to Monotonic Loading. 478 M.Sc. Thesis, Civil Engineering Department, Aalborg University.

479 Thieken, K., Achmus, M., and Schroder, C. 2014. On the behaviour of suction buckets in sands $480 \quad$ under tensile loads. Computer and Geotechnics, 60: 88-100.

481 Tjelta, T.I. 2015. The suction foundation technology. In Proceedings of the Third International 482 Symposium on Frontiers in Offshore Geotechnics, Oslo, 10-12 June 2015. CRC Press LLC, $483 \quad$ London, pp. 331-342.

484 Vaitkunaite, E. 2015. Test Procedure for Axially Loaded Bucket Foundations in Sand (Large 485 Yellow Box). DCE Technical Memorandum, No. 51, Department of Civil Engineering, $486 \quad$ Aalborg University, Aalborg. 
487 Vaitkunaite, E., Ibsen, L.B., and Nielsen, B.N. 2014. New Medium-Scale Laboratory Testing of 488 Bucket Foundation Capacity in Sand. In the Twenty-fourth International Ocean and Polar 489 Engineering Conference, Busan, 15-20 June 2015. International Society of Offshore and $490 \quad$ Polar Engineers, pp. 514-520.

491 Vaitkunaite, E., Nielsen, B.N., and Ibsen, L.B. 2016. Bucket Foundation Response under 492 Various Displacement Rates. International Journal of Offshore and Polar Engineering, $493 \quad 26(02): 116-124$

494 Vaitkunaite, E., Nielsen, B.N., and Ibsen, L.B. 2015. Comparison of design methods for axially 495 loaded buckets in sand. In Proceedings of the Third International Symposium on Frontiers in 496 Offshore Geotechnics, Oslo, 10-12 June 2015. CRC Press LLC, London, pp. 331-342.

497

498

499 List of symbols

$500 \quad D \quad$ is the bucket foundation diameter

$501 \quad D_{R} \quad$ is the sand relative density

$502 d \quad$ is the bucket foundation skirt length

$503 e_{\min }$ is the minimum void ratio

$504 e_{\max }$ is the maximum void ratio

$505 F_{c y c} \quad$ is the cyclic loading amplitude

$506 F_{\text {mean }}$ is the mean cyclic load

$507 \quad F_{P c}$ is the post-cyclic monotonic tensile capacity

$508 \quad F_{T} \quad$ is the monotonic peak tensile capacity

$509 \quad F_{T R} \quad$ is the reference monotonic tensile capacity

$510 f \quad$ is the loading frequency

$511 \mathrm{~g}$ is the acceleration of gravity

$512 \quad k_{10 \%} \quad$ is the tensile loading stiffness taken at $10 \%$ of the tensile loading

$513 \quad k_{\text {cyc }} \quad$ is the cyclic unloading stiffness

$514 \quad k_{\text {peak }} \quad$ is the peak tensile loading stiffness

$515 N$ is the number of cycles

$516 \quad t \quad$ is the bucket foundation skirt wall thickness

$517 \quad w_{i . d} \quad$ is the incremental displacement

$518 \quad V^{\prime} \quad$ is the effective soil unit weight

$519 \xi_{A} \quad$ is the ratio describing cyclic loading amplitude normalized with reference monotonic $520 \quad$ tensile load

$521 \xi_{m} \quad$ is the ratio describing mean cyclic load normalized with reference monotonic tensile 522 load 
Tables (2)

Table 1. Testing program.

\begin{tabular}{llllllllll}
\hline Test ID & Type & $\begin{array}{l}D_{R} \\
(\%)\end{array}$ & $\begin{array}{l}\gamma^{\prime} \\
\left(\mathrm{kN} / \mathrm{m}^{3}\right)\end{array}$ & $\begin{array}{l}F_{T} / F_{P c} \\
(\mathrm{kN})\end{array}$ & $\begin{array}{l}F_{\text {mean }} \pm F_{c y c}, f \\
(\mathrm{kN}, \mathrm{Hz})\end{array}$ & $\begin{array}{l}L R \\
(\mathrm{kN} / \mathrm{s})\end{array}$ & $\xi_{m}$ & $\xi_{A}$ & $\begin{array}{l}N \\
\left(\times 10^{3}\right)\end{array}$ \\
\hline St.1 & St & 80 & 9.3 & $-5.7 /-$ & - & $0.02^{\dagger}$ & - & - & - \\
St.2 & St & 80 & 9.5 & $-6.3 /-$ & - & $0.02^{\dagger}$ & - & - & - \\
St.3 & St & 84 & 9.6 & $-5.3 /-$ & - & $0.02^{\dagger}$ & - & - & - \\
St.4 & St & 85 & 9.6 & $-5.9 /-$ & - & $0.02^{\dagger}$ & - & - & - \\
A0.2m-0.4 & Cyc+Pc & 78 & 9.3 & $-/-5.3$ & $-2.1 \pm 1.0,0.1$ & 0.41 & -0.4 & 0.2 & 40.0 \\
A0.3m-0.4:1 & Cyc+Pc & 77 & 9.2 & $-/-5.7$ & $-2.1 \pm 1.9,0.1$ & 0.77 & -0.4 & 0.3 & 38.2 \\
A0.7m-0.4:1 & Cyc & 79 & 9.3 & pulled & $-2.1 \pm 3.9,0.1$ & 1.54 & -0.4 & 0.7 & 8.1 \\
A0.7m0.3:1* & Cyc & 85 & 9.6 & - & $1.8 \pm 3.9,0.1$ & 1.54 & 0.3 & 0.7 & 28.3 \\
A0.4m0.3 & Cyc+Pc & 78 & 9.3 & $-/-5.0$ & $1.9 \pm 2.3,0.05$ & 0.46 & 0.3 & 0.4 & 19.6 \\
A0.3m-0.4:2 & Cyc+Pc & - & 9.1 & $-/-4.7$ & $-2.1 \pm 1.9,0.1$ & 0.77 & -0.4 & 0.3 & 39.7 \\
A0.7m-0.4:2 & Cyc & - & 9.1 & pulled & $-2.1 \pm 3.9,0.1$ & 1.54 & -0.4 & 0.7 & 1.3 \\
A0.7m0.3:2 & Cyc+Pc & 81 & 9.4 & $-/-4.9$ & $1.8 \pm 3.9,0.1$ & 1.54 & 0.3 & 0.7 & 40.0 \\
A0.2m0 & Cyc+Pc & 81 & 9.4 & $-/-4.9$ & $0 \pm 1.00,0.1$ & 0.40 & 0 & 0.2 & 40.0 \\
\hline
\end{tabular}

Note: $\mathrm{St}-$ monotonic tensile test, Cyc - cyclic, Pc - Post-cyclic, $D_{R}-$ soil density ratio, $\gamma^{\prime}-$ soil unit weight, $F_{T / P c}$ - monotonic tensile peak load, $F_{\text {mean }}$ - mean cyclic load, $F_{c y c}$ - cyclic amplitude, $f$-load frequency, $L R$ - load rate, $N$ - cycle number.

*Test stopped after cycle No. 28,263; loading program was repeated in test A0.7m0.3:2.

${ }^{\dagger}$ Maximum load rate. 
Table 2. Displacement analysis.

\begin{tabular}{lllll}
\hline Test ID & $\xi_{m}$ & $\xi_{A}$ & $N$ & Comment for displacement \\
\hline $\mathrm{A} 0.7 \mathrm{~m} 0.3: 1$ & 0.3 & 0.7 & 160 & Developed constant $w_{i . d}$ of $10^{-6} \mathrm{~mm}$ \\
$\mathrm{~A} 0.7 \mathrm{~m} 0.3: 2$ & 0.3 & 0.7 & 200 & Developed constant $w_{i . d}$ of $10^{-6} \mathrm{~mm}$ \\
$\mathrm{~A} 0.4 \mathrm{~m} 0.3$ & 0.3 & 0.4 & 1100 & Developed constant $w_{i . d}$ of $10^{-6} \mathrm{~mm}$ \\
$\mathrm{~A} 0.2 \mathrm{~m} 0$ & 0 & 0.2 & 40 & Developed stable $w_{i . d}$ of $-10^{-7} \mathrm{~mm}$ \\
$\mathrm{~A} 0.3 \mathrm{~m}-0.4: 2$ & -0.4 & 0.3 & 188 & Developed stable $w_{i . d}$ of $-10^{-4} \mathrm{~mm}$ \\
$\mathrm{~A} 0.7 \mathrm{~m}-0.4: 1$ & -0.4 & 0.7 & - & Large displ. during all cycles \\
$\mathrm{A} 0.7 \mathrm{~m}-0.4: 2$ & -0.4 & 0.7 & - & Average $w_{i . d}$ of $-5 \cdot 10^{-2} \mathrm{~mm}$ \\
\hline
\end{tabular}

Note: $D_{R}-$ soil density ratio, $w_{i . d}$ - incremental displacement, $N$ - cycle number to reach a constant $w_{i . d}$. 


\section{List of Figures (19)}

Fig. 1. Test set-up plan (Vaitkunaite 2015).

Fig. 2. Bucket model used for the testing: pressure transducer (1), valves (2), displacement transducers (3), positions for the pore pressure measurements (PP1-PP7); dimensions in $\mathrm{mm}$.

Fig. 3. Sieve analysis of Aalborg University Sand No. 1. performed in 2012.

Fig. 4. Model installation with preload and elastic unload, test A0.7m0.3:1.

Fig. 5. The definition of loading parameters.

Fig. 6. Monotonic tensile loading tests and pore pressure development under the bucket model lid vs. upward displacement (tests St.1, St.2, St.3 and St.4).

Fig. 7. Full loading program for test A0.2m0: Load and pore pressure vs. upward displacement.

Fig. 8. Accumulated displacement vs. number of cycles (tests A0.3m-0.4:1, A0.3m-0.4:2, A0.7m-0.4:1, and A0.7m$0.4: 2)$

Fig. 9. Incremental and accumulated displacement vs. number of cycles, test A0.7m0.3:2.

Fig. 10. Incremental and accumulated displacement vs. number of cycles, test A0.7m-0.4:2.

Fig. 11. Virgin and post-cyclic monotonic shaft friction vs. upward displacement.

Fig. 12. Pore pressure development during cyclic loading (tests A0.2m-0.4, A0.3m-0.4:2 and A0.7m-0.4:2).

Fig. 13. Accumulated displacement and pore pressure vs cyclic loading in test A0.7m-0.4:2.

Fig. 14. Accumulated displacement and pore pressure vs cyclic loading in test A0.7m-0.4:1.

Fig. 15. Cyclic unloading stiffness (a), Monotonic loading stiffness (b).

Fig. 16. Unloading stiffness vs cycles for tests A0.7m-0.4:2 and A0.7m0.3:2.

Fig. 17. The normalized cycles of tests A0.7m0.3:2 (black) and A0.7m-0.4:2 (grey).

Fig. 18. Normalized unloading stiffness vs. cycle number during the first 200 cycles.

Fig. 19. Normalized accumulative displacements vs. cycle number during the first 200 cycles. 


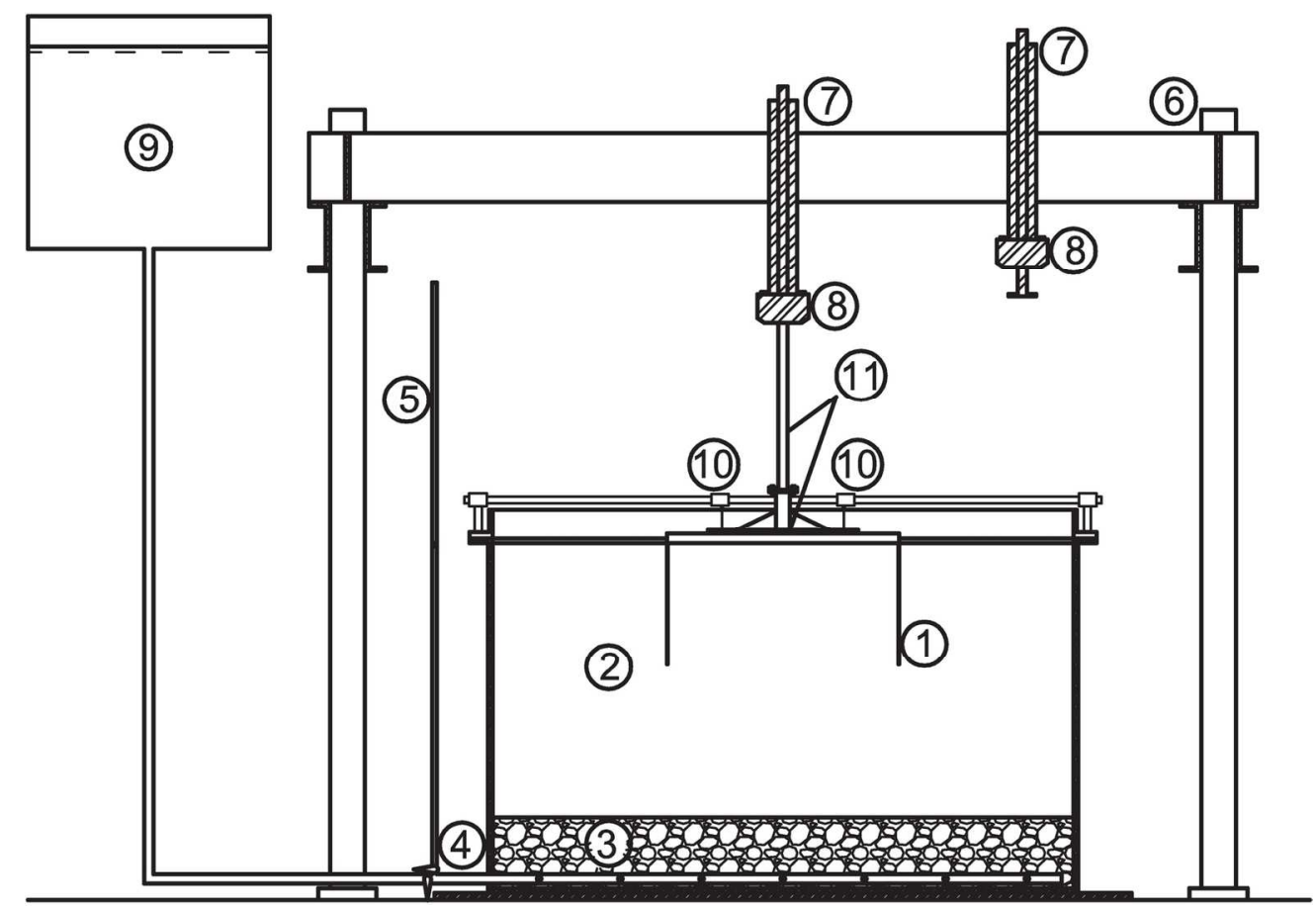

(1) Bucket

(4) Drainage system

(7) Hydraulic piston

(2) Saturated sand

(5) Ascension pipe

(8) Load cell

(3) Saturated gravel

(6) Load frame

(9) Water tank

(10) Displacement transducer (11) Connecting flange

Fig. 1. Test set-up plan (Vaitkunaite 2015).

Fig. 1

$148 \times 133 \mathrm{~mm}(300 \times 300 \mathrm{DPI})$ 

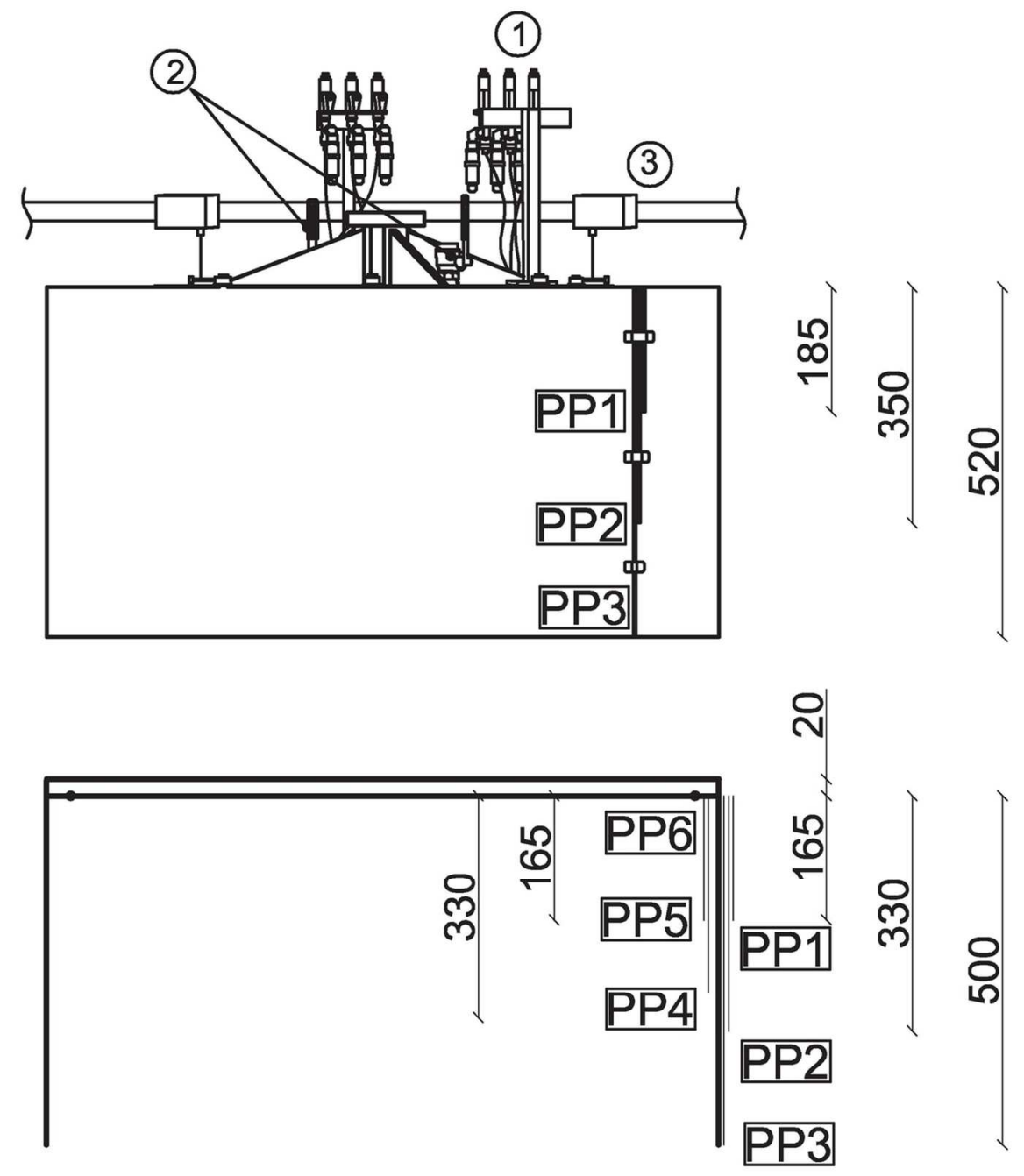

Fig. 2. Bucket model used for the testing: pressure transducer (1), valves (2), displacement transducers (3), positions for the pore pressure measurements (PP1-PP7); dimensions in $\mathrm{mm}$.

Fig. 2

$118 \times 129 \mathrm{~mm}(300 \times 300 \mathrm{DPI})$ 


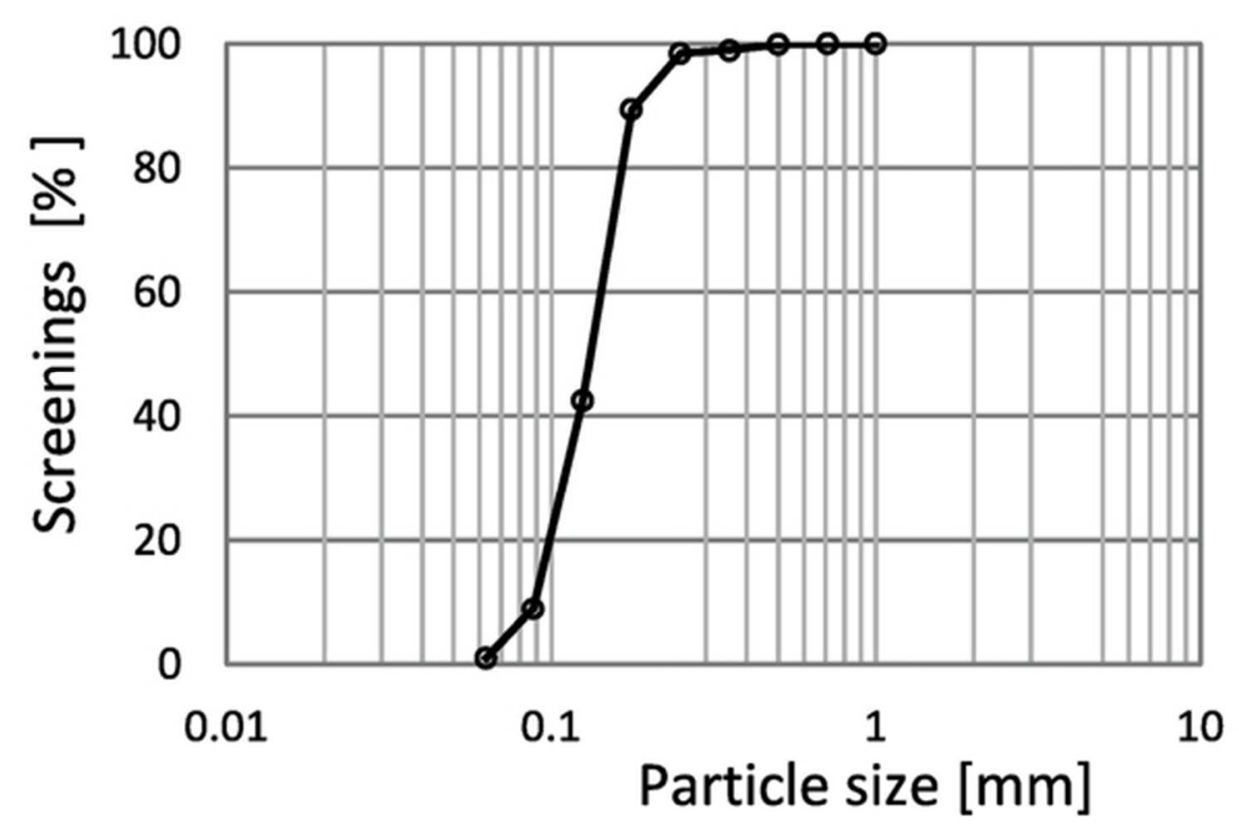

Fig. 3. Sieve analysis of Aalborg University Sand No. 1. performed in 2012.

Fig. 3

$53 \times 34 \mathrm{~mm}(300 \times 300 \mathrm{DPI})$ 


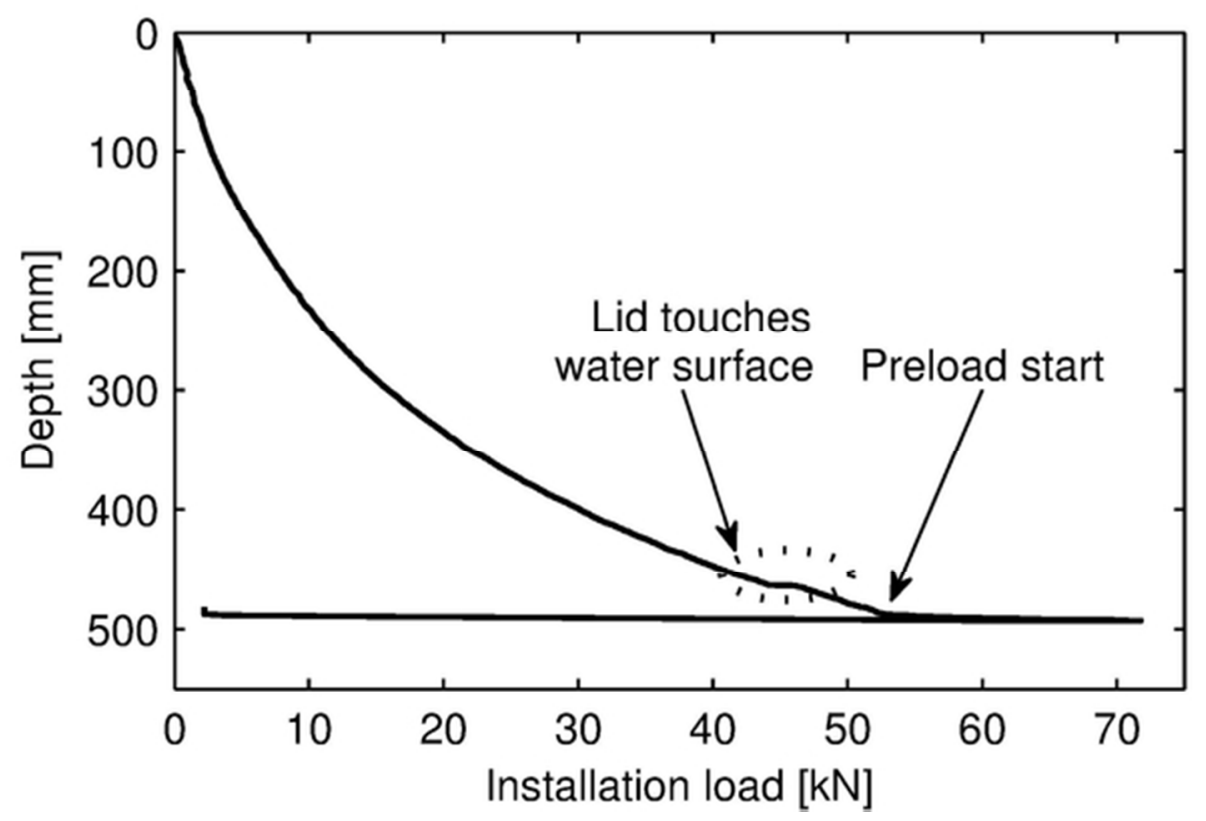

Fig. 4. Model installation with preload and elastic unload, test A0.7m0.3:1. Fig. 4

$55 \times 35 \mathrm{~mm}(300 \times 300$ DPI $)$ 


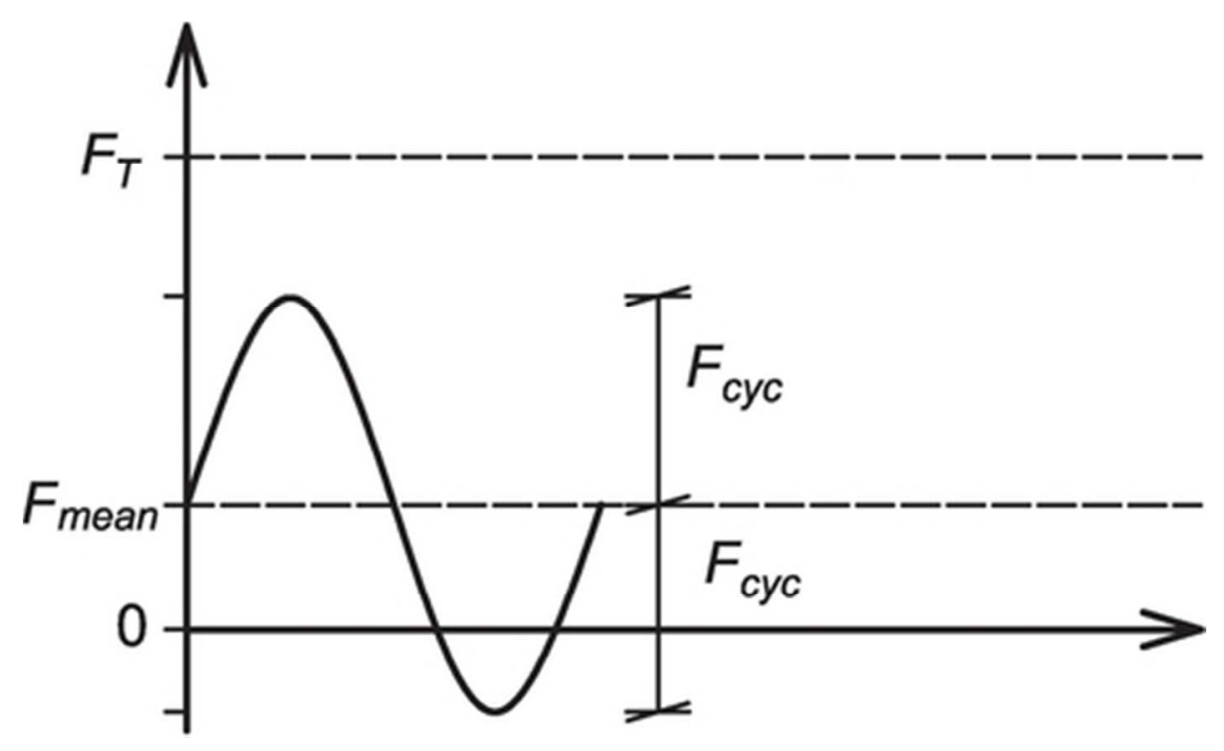

Fig. 5. The definition of loading parameters.

Fig. 5

$38 \times 23 \mathrm{~mm}(300 \times 300$ DPI $)$ 


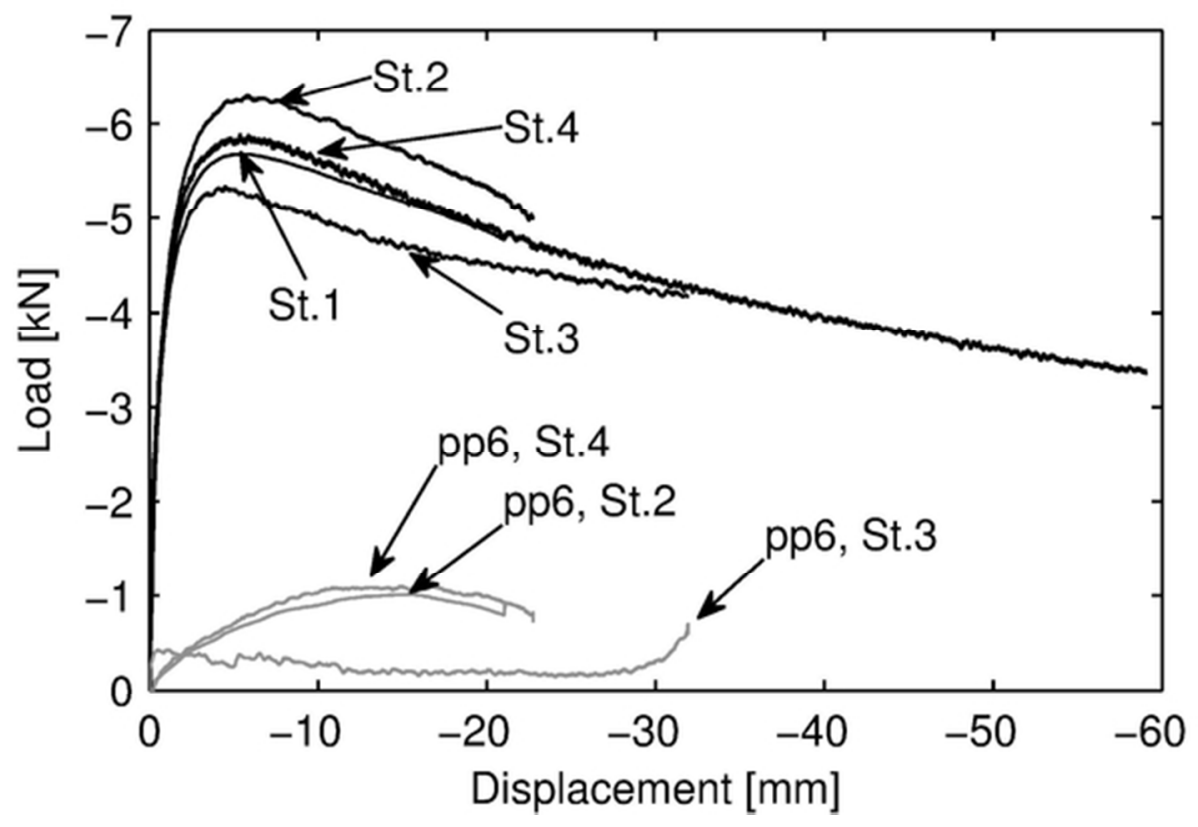

Fig. 6. Monotonic tensile loading tests and pore pressure development under the bucket model lid vs. upward displacement (tests St.1, St.2, St.3 and St.4).

Fig. 6

$55 \times 35 \mathrm{~mm}(300 \times 300 \mathrm{DPI})$ 


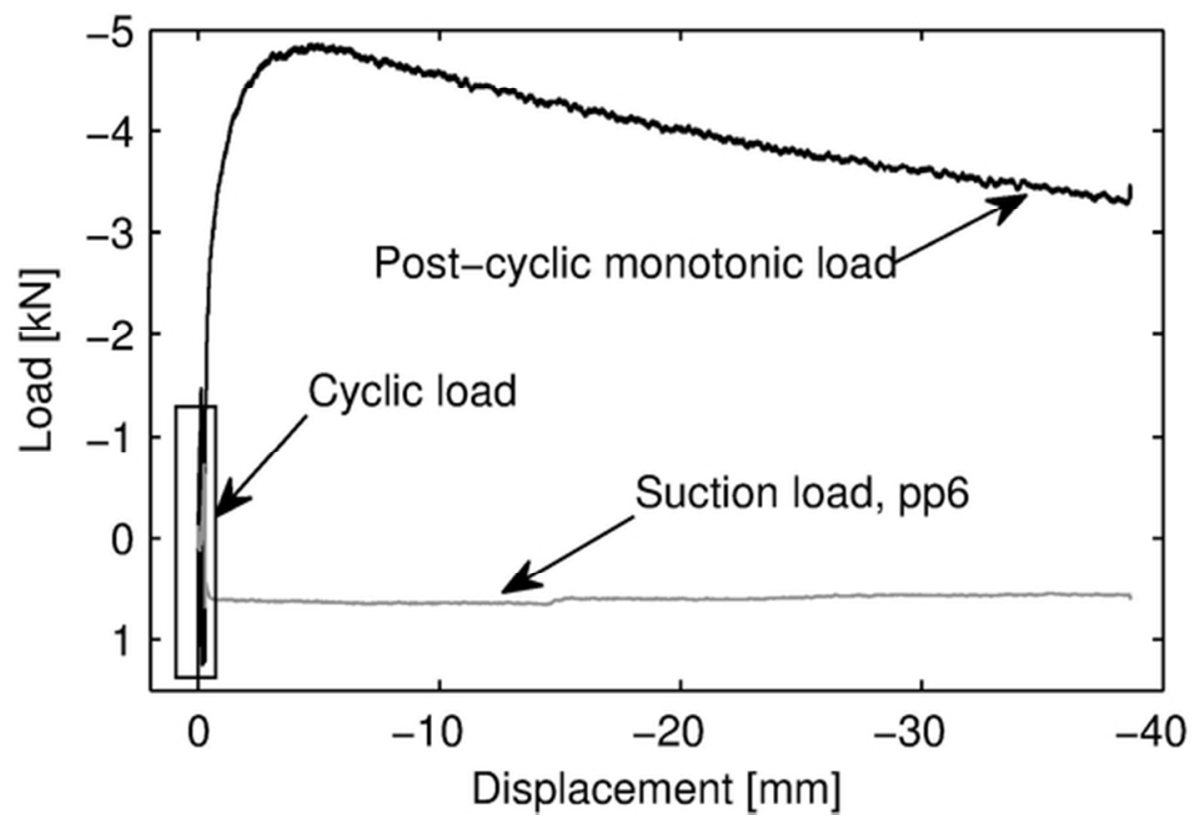

Fig. 7. Full loading program for test A0.2m0: Load and pore pressure vs. upward displacement. Fig. 7

$55 \times 35 \mathrm{~mm}(300 \times 300$ DPI $)$ 


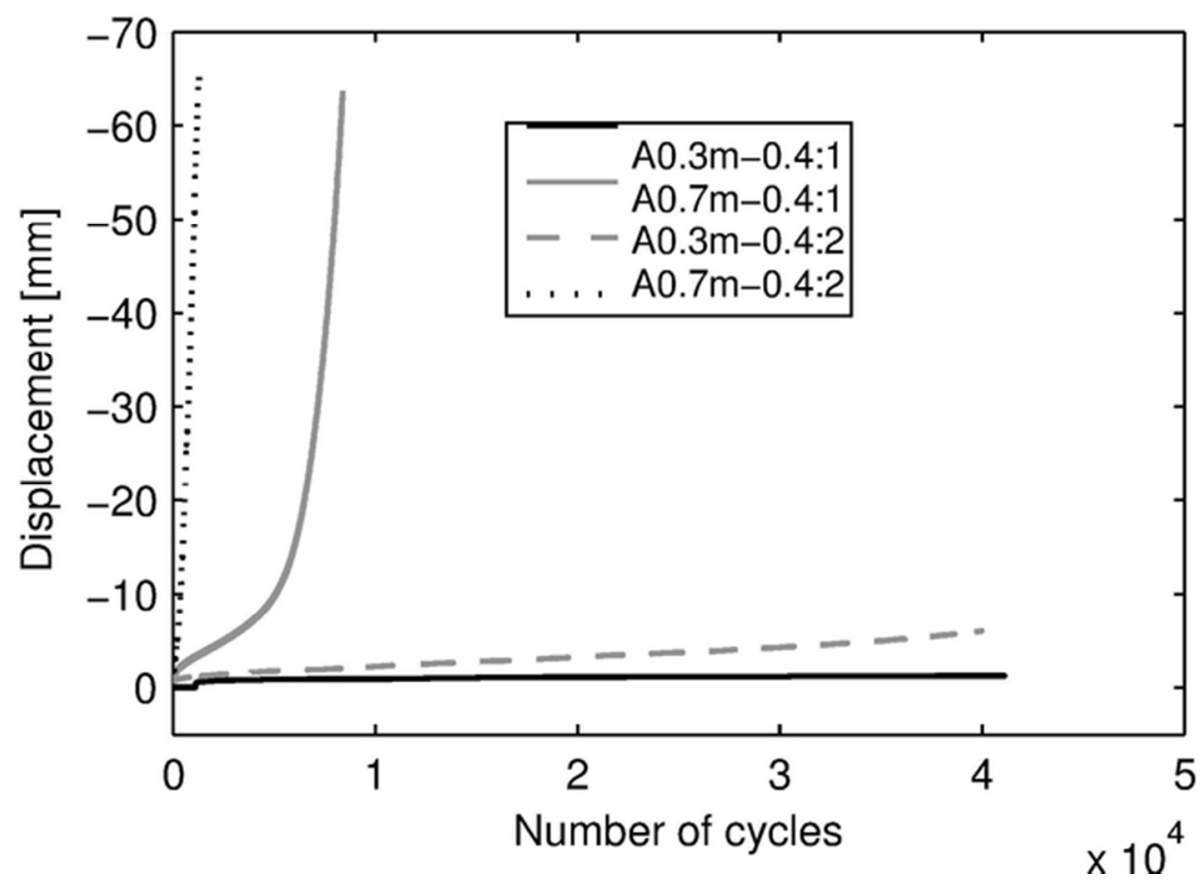

Fig. 8. Accumulated displacement vs. number of cycles (tests A0.3m-0.4:1, A0.3m-0.4:2, A0.7m-0.4:1, and $\mathrm{A} 0.7 \mathrm{~m}-0.4: 2)$.

Fig. 8

$59 \times 41 \mathrm{~mm}(300 \times 300 \mathrm{DPI})$ 

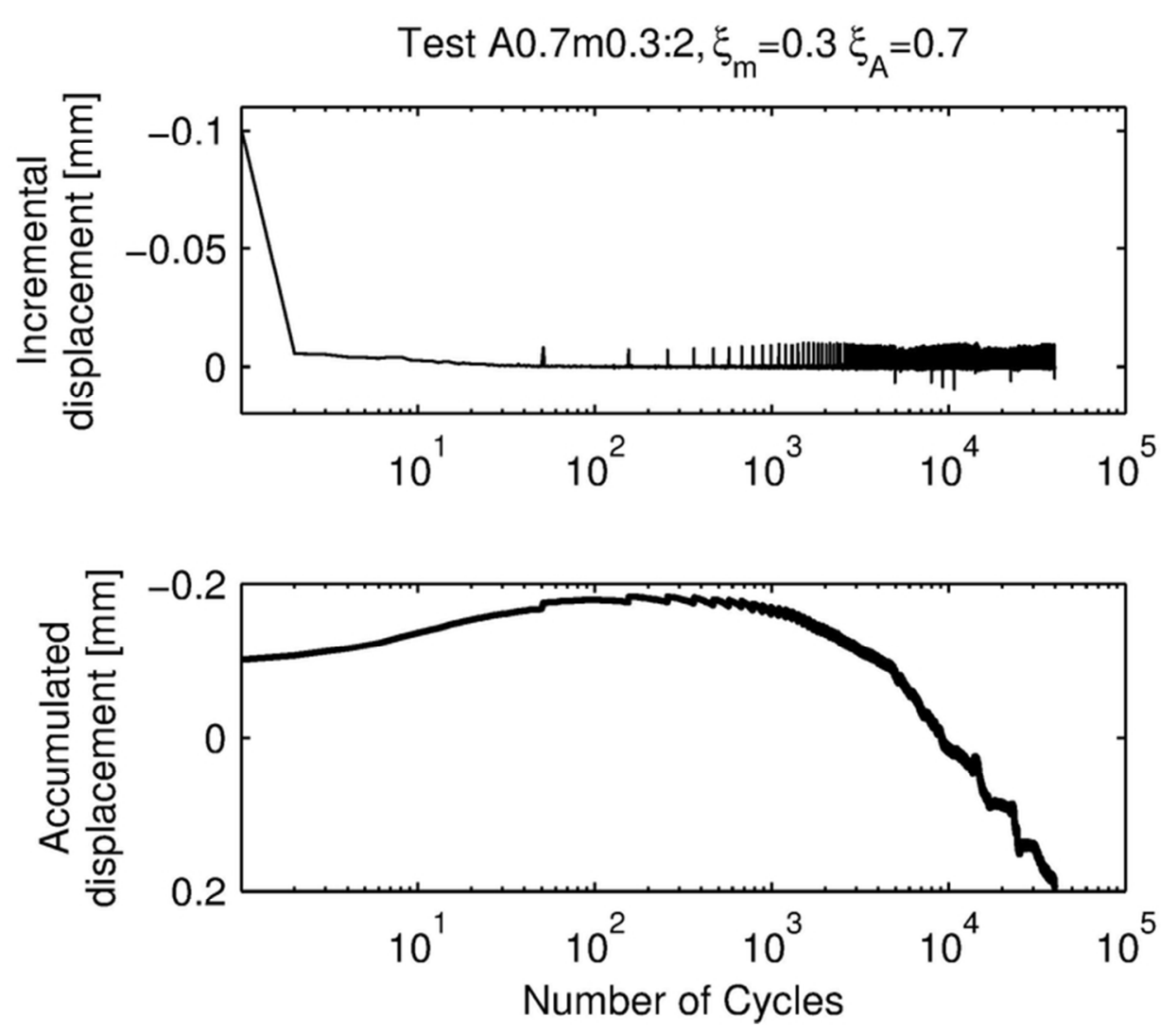

Fig. 9. Incremental and accumulated displacement vs. number of cycles, test A0.7m0.3:2. Fig. 9

$70 \times 57 \mathrm{~mm}(300 \times 300 \mathrm{DPI})$ 
Test A0.7m-0.4:2, $\xi_{m}=-0.4 \xi_{A}=0.7$
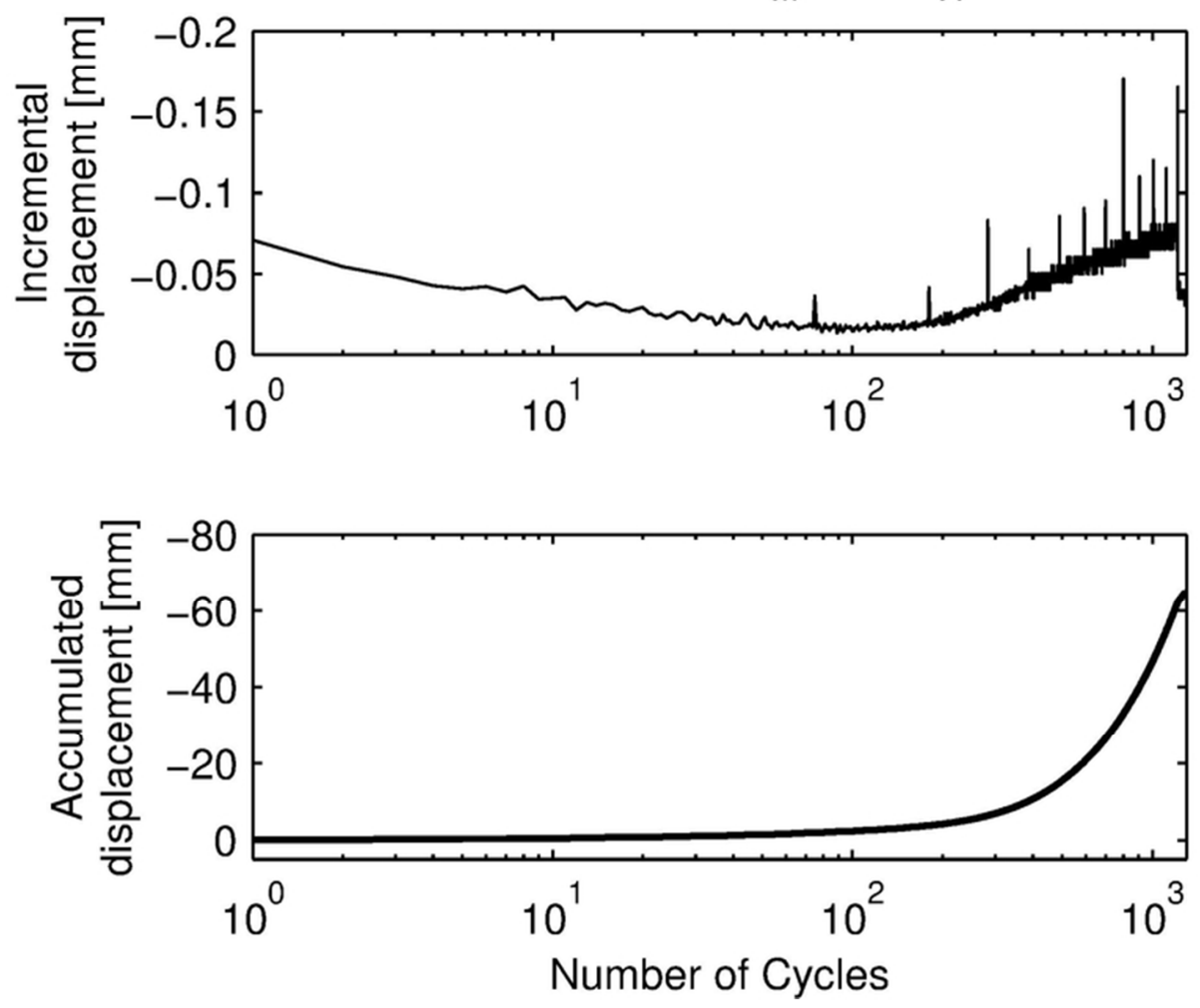

Fig. 10. Incremental and accumulated displacement vs. number of cycles, test A0.7m-0.4:2. Fig. 10

$70 \times 57 \mathrm{~mm}(300 \times 300 \mathrm{DPI})$ 


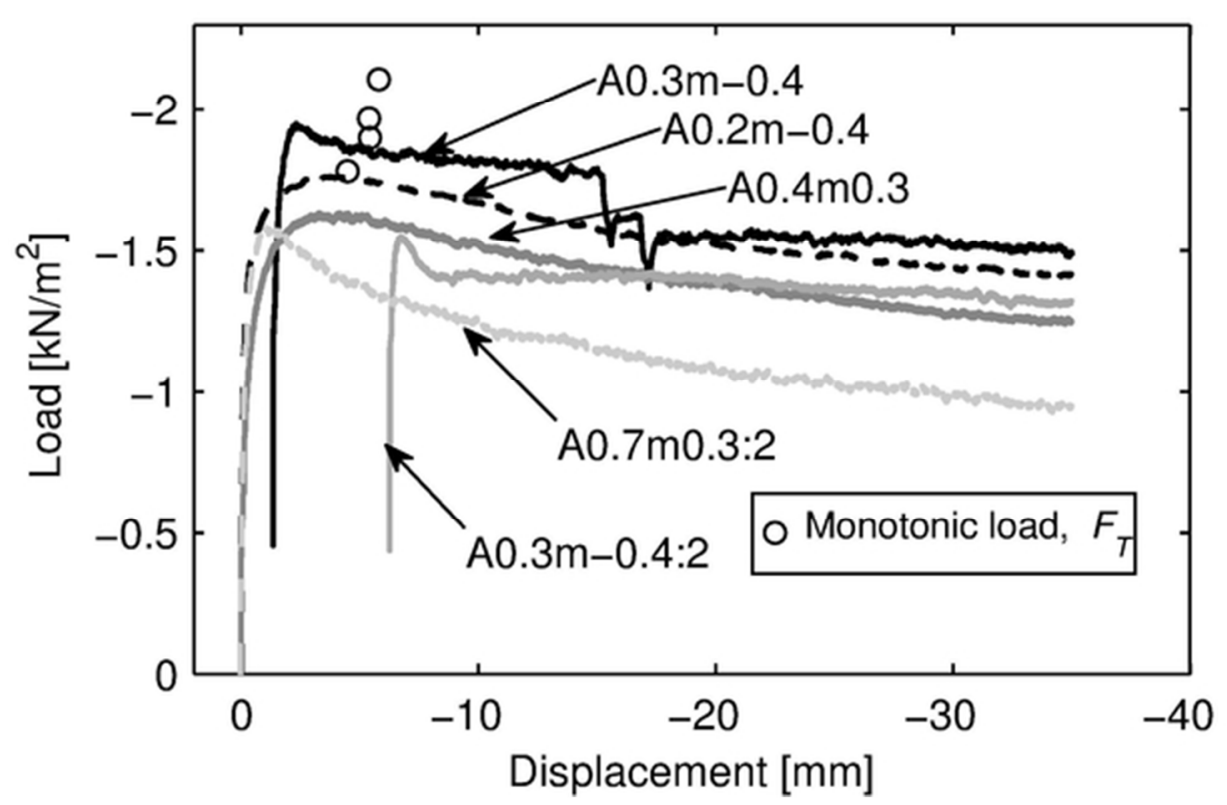

Fig. 11. Virgin and post-cyclic monotonic shaft friction vs. upward displacement. Fig. 11

$55 \times 35 \mathrm{~mm}(300 \times 300$ DPI $)$ 


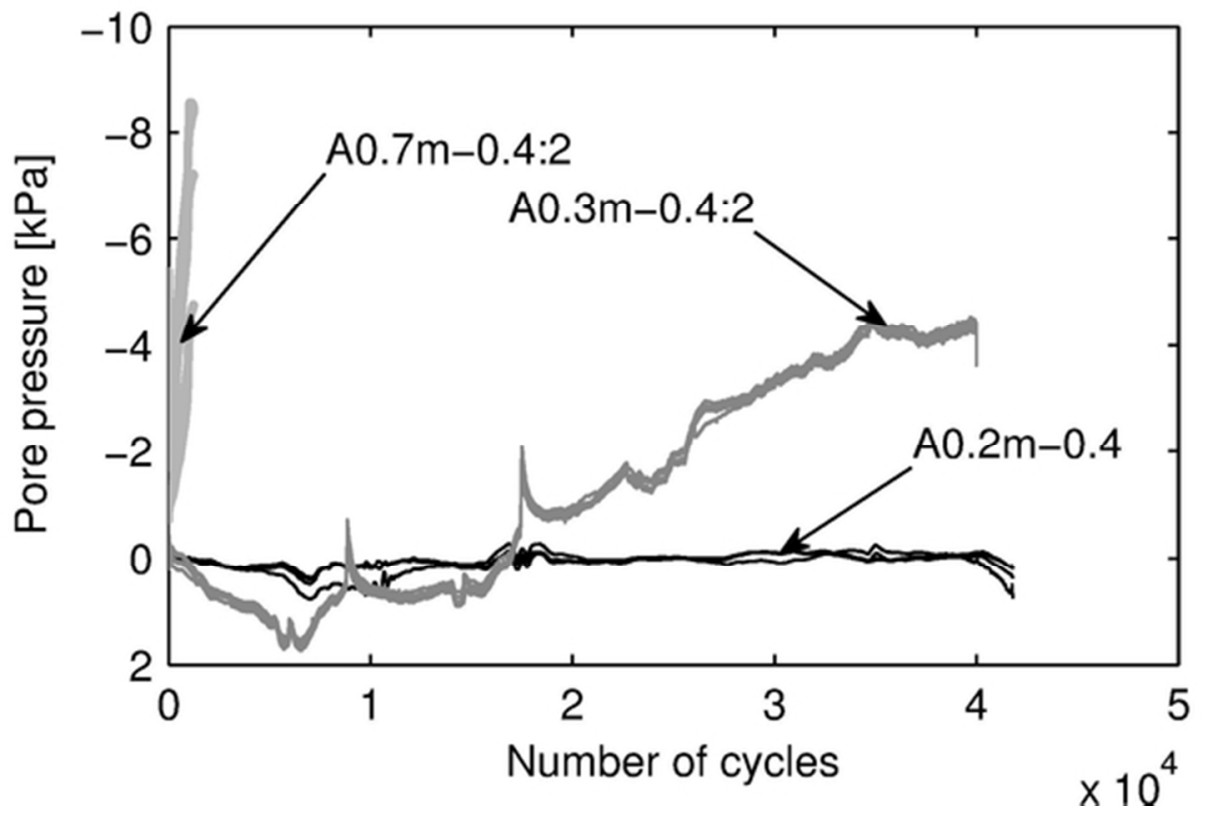

Fig. 12. Pore pressure development during cyclic loading (tests $A 0.2 m-0.4, A 0.3 m-0.4: 2$ and $A 0.7 m-0.4: 2$ ). Fig. 12

$55 \times 35 \mathrm{~mm}(300 \times 300$ DPI $)$ 

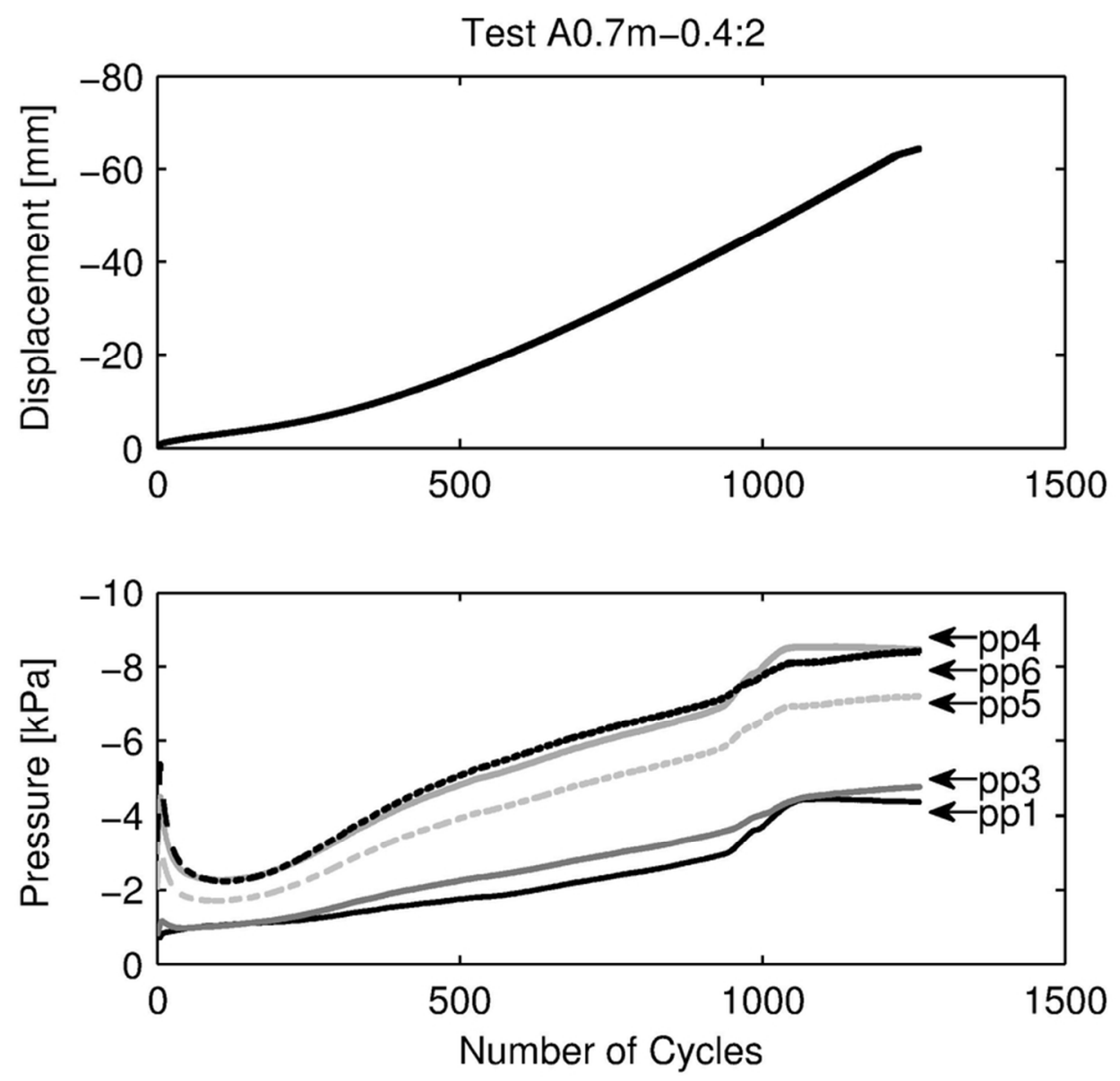

Fig. 13. Accumulated displacement and pore pressure vs cyclic loading in test A0.7m-0.4:2. Fig. 13

$79 \times 74 \mathrm{~mm}(300 \times 300 \mathrm{DPI})$ 

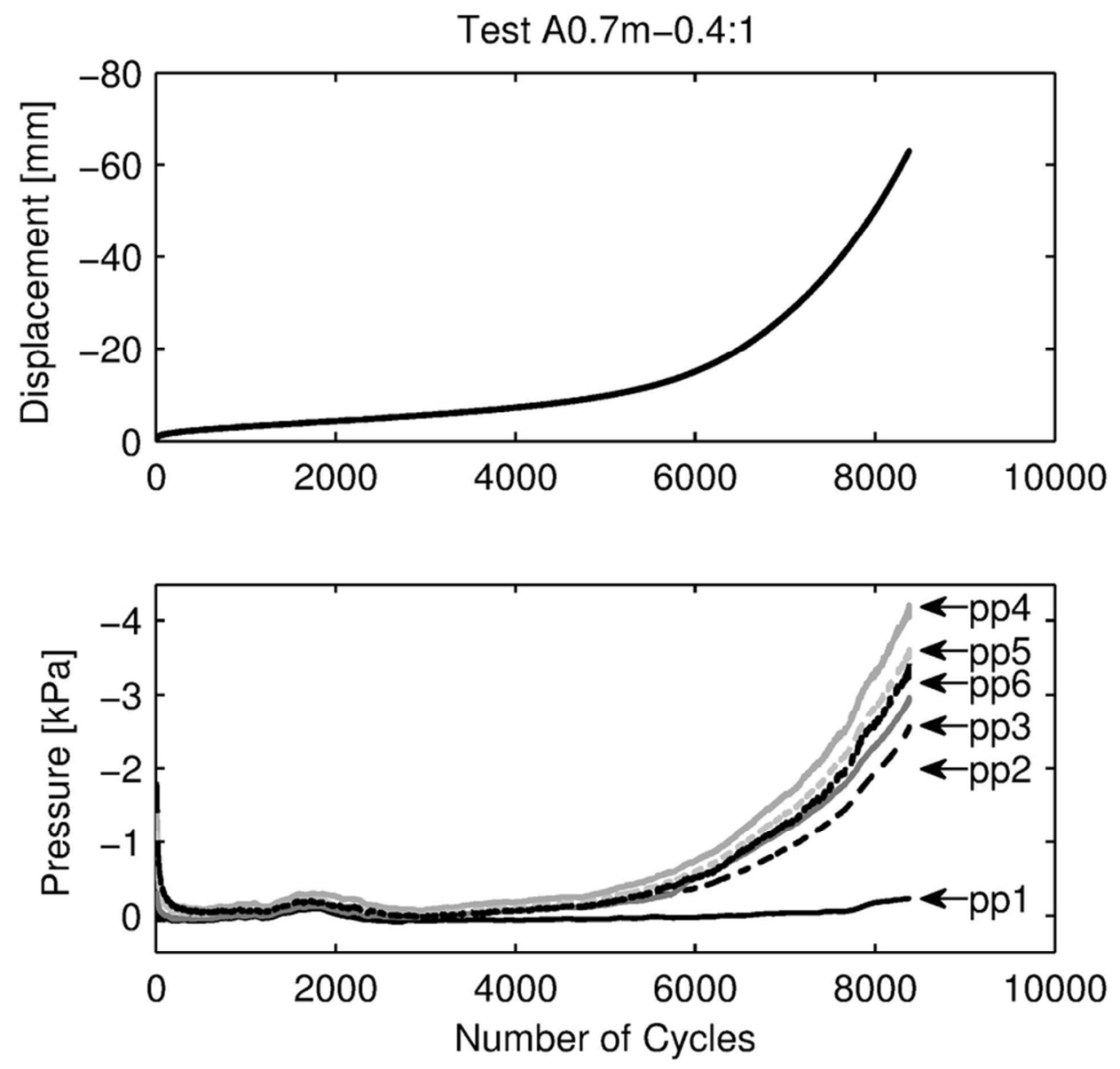

Fig. 14. Accumulated displacement and pore pressure vs cyclic loading in test A0.7m-0.4:1. Fig. 14

$79 \times 74 \mathrm{~mm}(300 \times 300 \mathrm{DPI})$ 


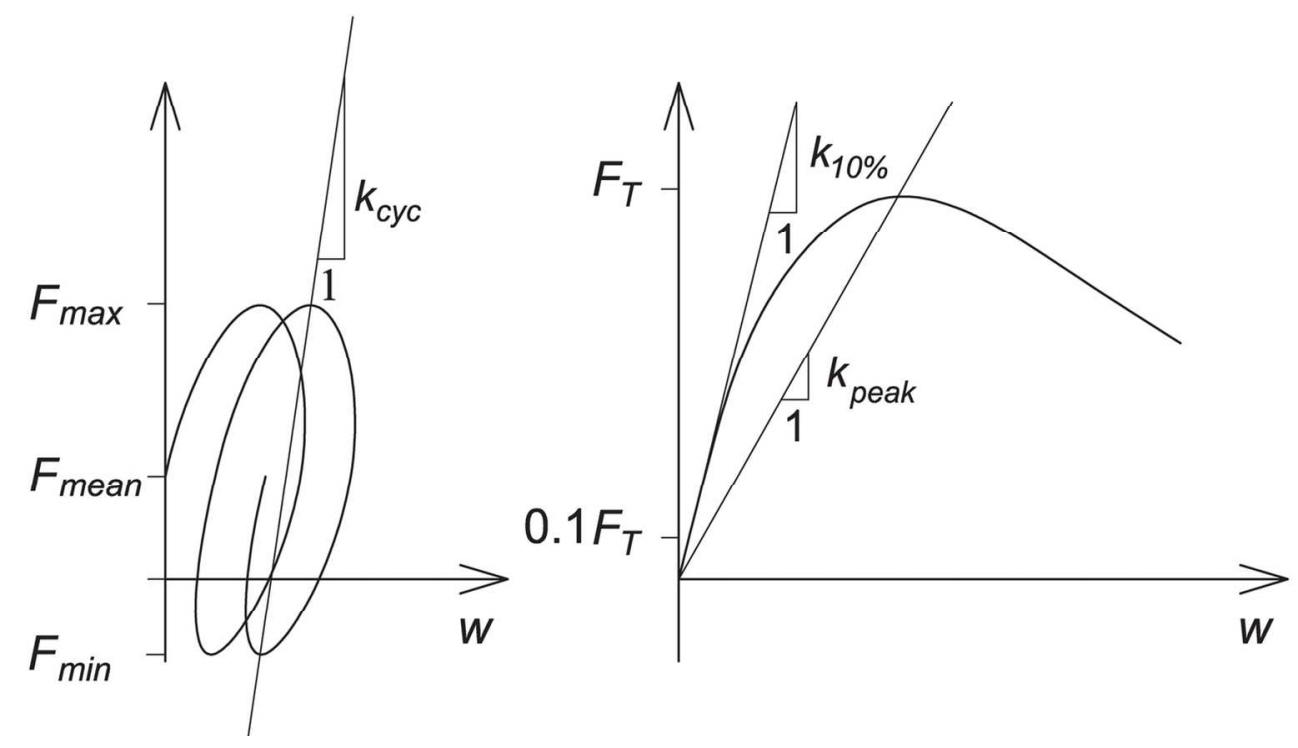

Fig. 15. Cyclic unloading stiffness (a), Monotonic loading stiffness (b).

Fig. 15

$126 \times 73 \mathrm{~mm}(300 \times 300$ DPI $)$ 


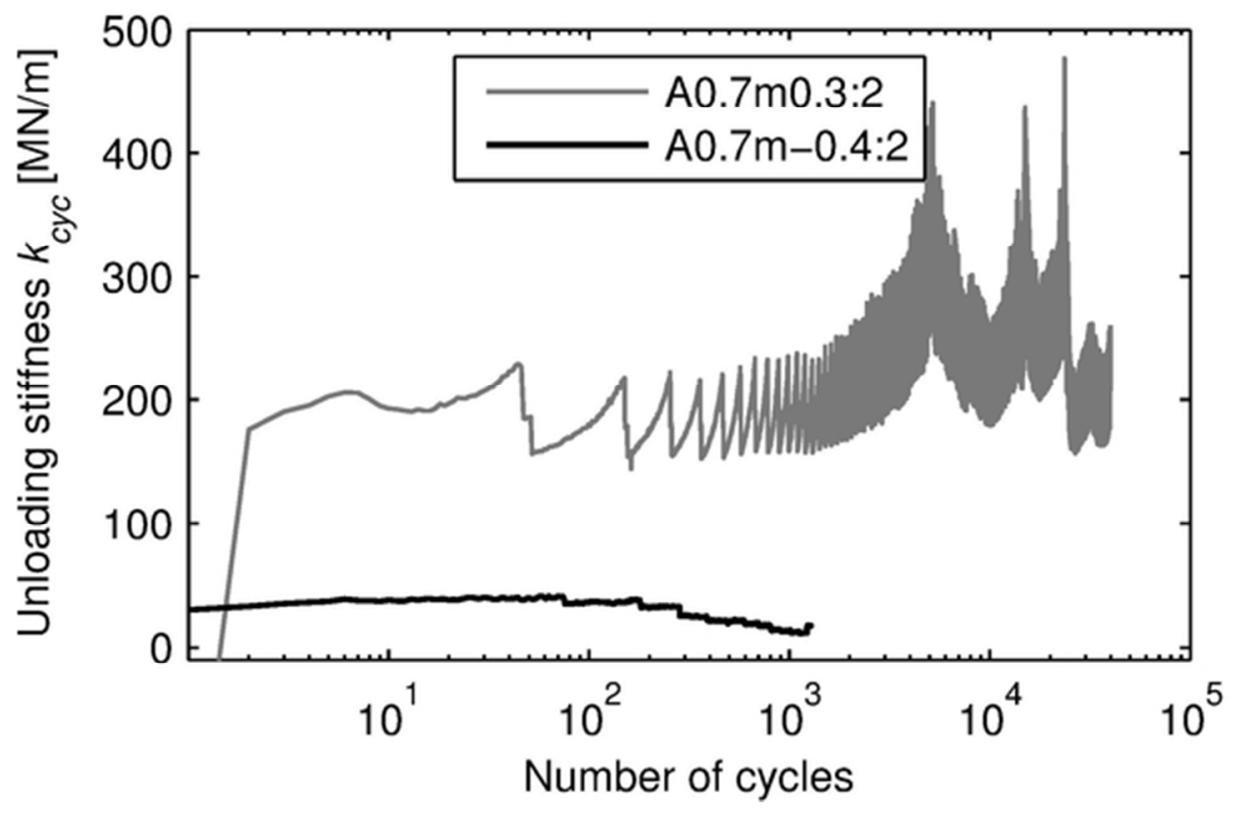

Fig. 16. Unloading stiffness vs cycles for tests A0.7m-0.4:2 and A0.7m0.3:2. Fig. 16 $55 \times 35 \mathrm{~mm}(300 \times 300$ DPI $)$ 


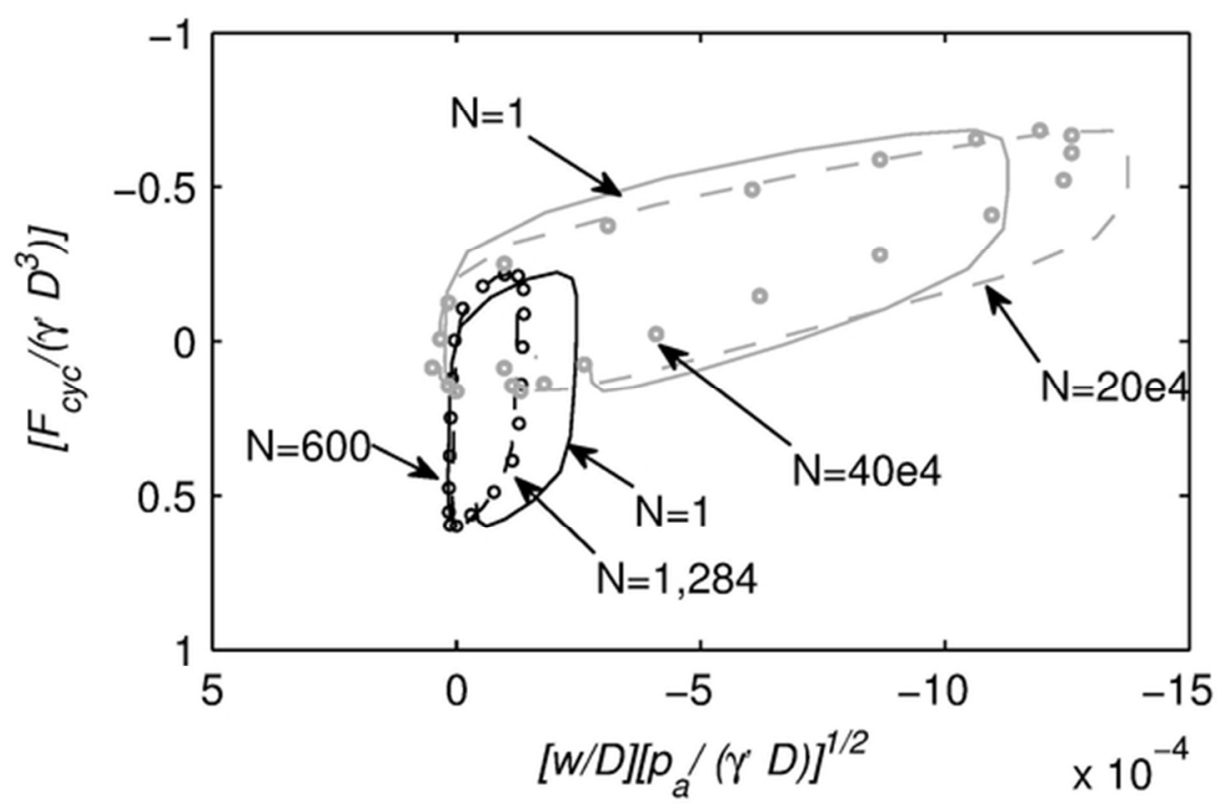

Fig. 17. The normalized cycles of tests $A 0.7 \mathrm{~m} 0.3: 2$ (black) and A0.7m-0.4:2 (grey). Fig. 17 $55 \times 35 \mathrm{~mm}(300 \times 300 \mathrm{DPI})$ 


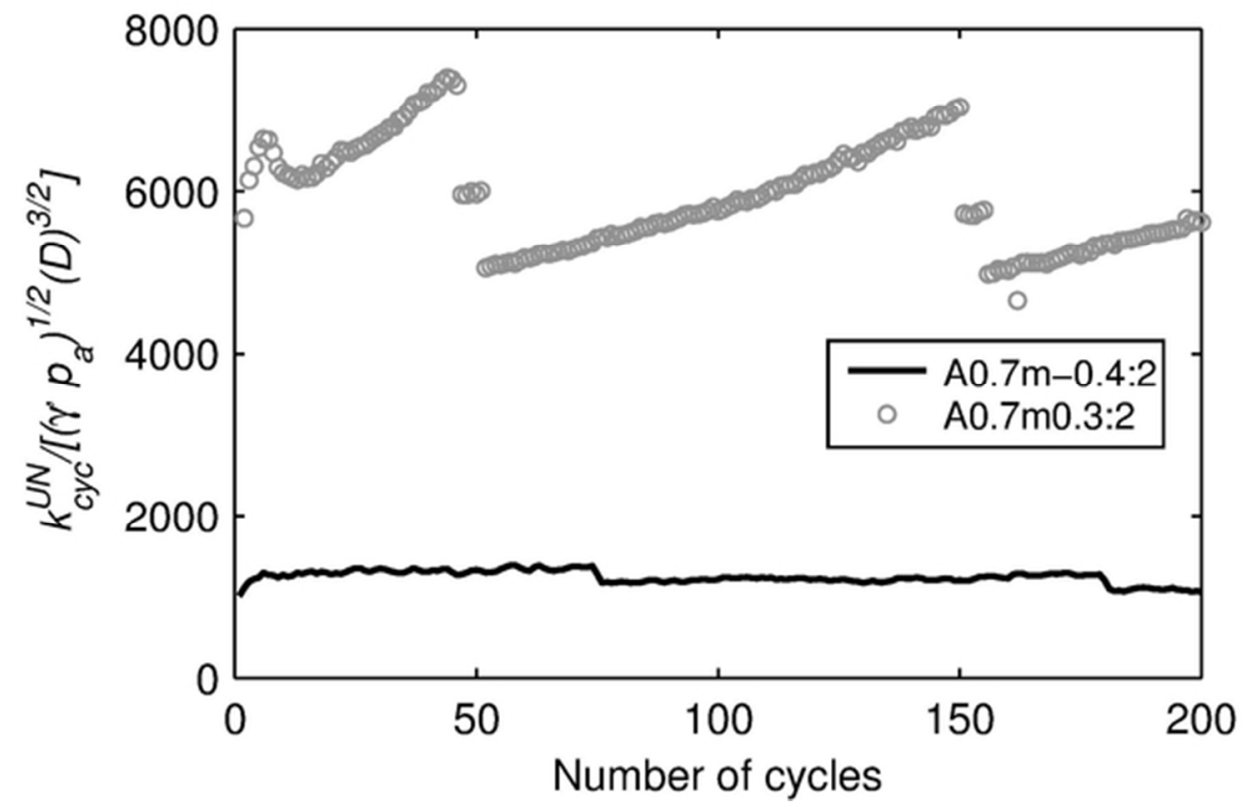

Fig. 18. Normalized unloading stiffness vs. cycle number during the first 200 cycles. Fig. 18 $55 \times 35 \mathrm{~mm}(300 \times 300 \mathrm{DPI})$ 


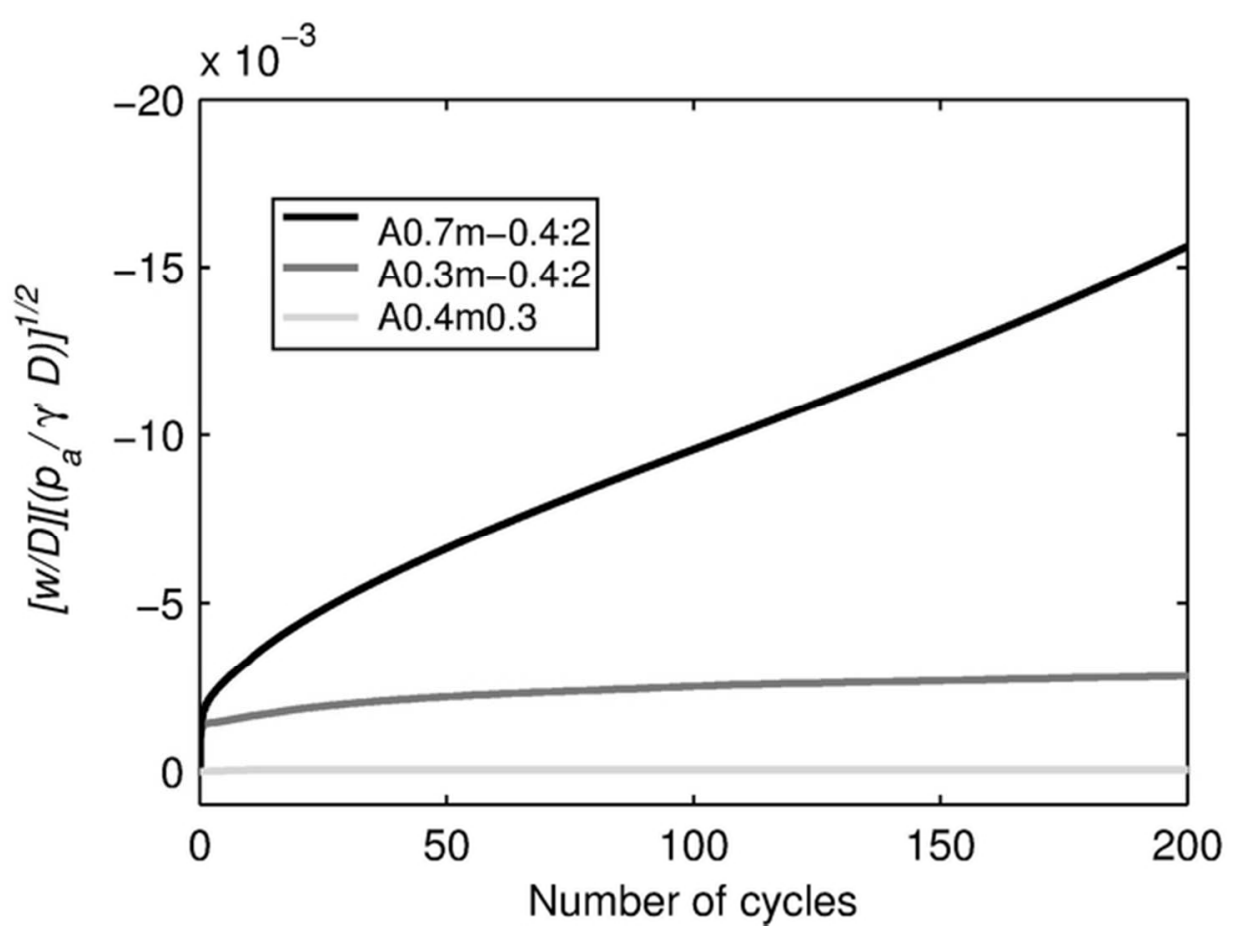

Fig. 19. Normalized accumulative displacements vs. cycle number during the first 200 cycles. Fig. 19

$59 \times 41 \mathrm{~mm}(300 \times 300$ DPI $)$ 